\title{
Numerical investigation of a solar dish concentrator with different cavity receivers and working fluids
}

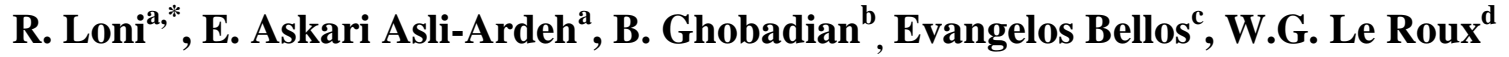 \\ ${ }^{a}$ Department of Mechanic of Biosystems Engineering, University of Mohaghegh Ardabili, \\ Ardabil, Iran. \\ ${ }^{b}$ Department of Mechanic of Biosystems Engineering, Tarbiat Modares University, Tehran, Iran. \\ ${ }^{c}$ Thermal Department, School of Mechanical Engineering, National Technical University of \\ Athens, Zografou, Heroon Polytechniou 9, 15780 Athens, Greece. \\ ${ }^{\mathrm{d}}$ Department of Mechanical and Aeronautical Engineering, University of Pretoria, Pretoria, \\ South Africa.
}

Corresponding Author: R. Loni (rloni@uma.ac.ir , Tel: +98-9188480327)

\begin{abstract}
Solar concentrating technologies can produce heat for applications such as solar heating, solar cooling, industrial processes, desalination and electric power generation. For a solar dish collector, various solar receivers and working fluids at different flow rates can be used in different applications. In this work, three different cavity receivers are investigated for application in a solar dish collector using either water or Behran oil. A numerical model is used in the analysis, which is validated with experimental results from a hemispherical cavity receiver using oil as working fluid. The model is applied to compare hemispherical, cylindrical and cubical receivers under the same operating conditions using either water or oil, at a volumetric flow rate of $100 \mathrm{ml} / \mathrm{s}$ and solar irradiance of $800 \mathrm{~W} / \mathrm{m}^{2}$, in order to determine the most suitable cavity for a specific solar dish. The system is investigated for inlet temperatures ranging from $40^{\circ} \mathrm{C}$ to $90^{\circ} \mathrm{C}$ with water as working fluid, and from $40^{\circ} \mathrm{C}$ to $300^{\circ} \mathrm{C}$ with Behran oil as working fluid. Emphasis is placed on the calculation of useful heat production, as well as pressure drop which influences pumping power. The exergetic efficiency criterion and the overall efficiency criterion are used in order to evaluate the useful heat production and the pumping power simultaneously. The high exergetic efficiency of the hemispherical cavity with thermal oil at high temperatures makes this case a promising choice for high-temperature solar dish collector applications. Moreover, water is found to be the best candidate for low-temperature applications since it leads to higher thermal efficiency with lower pumping power demand.
\end{abstract}

\section{Keywords}

Solar dish, Cavity absorber, Exergy analysis, Pressure drop, Thermal oil

\section{Introduction}

Solar energy utilization is one of the most promising ways for facing recent problems which are associated with global warming, fossil fuel depletion, increasing energy demand and high electricity prices [1]. The main advantages of solar energy are its abundance [2] and the 
possibility for direct conversion either to useful heat or to electricity [3]. The solar thermal energy exploitation can be performed either with non-concentrating technologies or concentrating technologies. The non-concentrating technologies are separated into flat plate collectors for operation of up to $90^{\circ} \mathrm{C}[4]$ and evacuated tube collectors for operation of up to $150^{\circ} \mathrm{C}$ [5]. Solar concentrating technologies are ideal solutions for producing heat at medium and high temperatures (usually up to $400-500^{\circ} \mathrm{C}$ ) [6] for covering the energy needs in a great range of applications such as solar heating, solar cooling, industrial processes, desalination and electric power generation. The most common concentrating collectors are parabolic trough collectors, linear Fresnel reflectors, solar dishes and solar towers [7].

In recent years, much research has been focused on solar dish collectors as compact technologies which can produce heat at high temperatures. Solar dishes present high concentration ratios compared to linear technologies and are therefore promising for driving high-temperature applications. It is for this reason that the determination of the optimum design in order to maximize the optical and the thermal efficiency of solar dish collectors is a popular research topic. This technology is under development and numerous interesting ideas have been tested over the past few years in different parts of the world.

The first part of the literature study is focused on the optimization of the collector concentrator. Different ideas have been considered in order to achieve a compact and low-cost technology. Moreover, the creation of a relatively uniform heat flux distribution on the absorber is an additional goal of many design procedures. Schmitz et al. [8] designed a solar dish collector with elliptical vacuum membrane facets in order to reduce the manufacturing costs of the system. Their system was able to produce $4.1 \mathrm{~kW}$ of useful heat with maximum local concentration ratio close to 900. Cohen and Grossman [9] considered a stationary spherical concentrator with a receiver that changes position in order to follow the sun's image. This system is able to produce industrial heat in temperature ranges of up to $300^{\circ} \mathrm{C}$ with high efficiency in the range of $70 \%$ $80 \%$. Chandrashekara et al. [10] studied a special graphite solar coating in a Scheffler dish and they proved high durability up to temperatures of $750^{\circ} \mathrm{C}$. Yu et al. [11] studied a solar dish concentrator with a compound primary reflector which consists of 31 small dishes. Wang et al. [12] examined a two-stage solar dish receiver in order to design a compact system with small focal distance. Moreover, Prenzak et al. [13] carried out an interesting work about a double solar dish concentrator with a novel receiver geometry.

The next part of the literature study is focused on the optimization of the receiver. The receiver has to be designed in such a way that it will lead to high optical efficiency and to low heat losses. The shape and the dimensions of receivers are investigated in the literature study in order to achieve a design which absorbs the maximum possible solar energy while having a low external area in order to lose less heat. Moreover, the optimum design needs a relatively uniform temperature profile in order to minimize the temperature and heat flux peaks which are responsible for increased radiation heat loss. Various absorber shapes have been examined in the literature, such as cylindrical, conical, rectangular, spiral and spherical. 
The most common absorber shape is a cylindrical cavity and this configuration has been examined by various researchers. Loni et al. [14] examined a cylindrical cavity receiver which delivers useful heat in an organic Rankine cycle. The objective of this work was the optimization of the cavity shape and finally, the optimum cavity diameter was found. In the same direction, Zou et al. [15] examined the optimum values of cylindrical cavity receivers. Prakash et al. [16] carried out thermal analysis of cylindrical cavities and they found that convective losses have a high impact on thermal efficiency. Mawire and Taole [17] investigated a cylindrical cavity receiver with an optical efficiency of close to $52 \%$ and, according to their results, a heat loss factor of $4.6 \mathrm{~W} / \mathrm{K}$. Azzouzi et al. [18] performed a parametric analysis of the impact of various parameters on the efficiency of a solar dish collector with a cylindrical cavity.

Tan et al. [19] investigated the use of a semi-spherical cavity receiver for temperatures of up to $300^{\circ} \mathrm{C}$. Emphasis was given on convective heat losses and Nusselt number correlations were developed. Reddy et al. [20-21] examined the heat losses of spherical receivers with a modified cavity. The use of a spiral coil absorber was studied by Pavlovic et al. [22-24]. The absorber was investigated experimentally and numerically and it was found that the optimum operating temperature is close to $150^{\circ} \mathrm{C}$ according to exergetic criteria. In Refs. [22-23] the system was experimentally investigated, while in Ref. [24] a theoretical parametric investigation was performed.

Other cavities have also been investigated in the literature. Loni et al. [25] investigated a prismatic cavity receiver and a tubular cavity receiver [26]. Xu et al. [27] examined a tapered tube bundle receiver for operation at high temperatures. Zhu et al. [28] studied a pressurized volumetric solar receiver which reaches up to $36 \%$ exergetic efficiency with an outlet temperature of $480^{\circ} \mathrm{C}$. Wang et al. [29] designed a windowed volumetric solar receiver which can reach a thermal efficiency of up to $63 \%$ with an air outlet temperature of $1003 \mathrm{~K}$. Furthermore, it is important to state that there are comparison studies of different cavity receivers in the literature. Shuai et al. [30-31] compared cylindrical, dome, heteroconical, elliptical, conical and spherical receivers. According to their results, the spherical receiver has the most uniform heat flux distribution. On the other hand, Daabo et al. [32-33] found the conical shape to be more beneficial than the cylindrical and the spherical designs.

The previous literature review indicates that there is great interest in the determination of the optimum design of the solar dish collector. In this direction, the objective of this work is to investigate three different cavity receivers (hemispherical, cylindrical and cubical) optically, thermally and exergetically for operation with water and thermal oil as working fluids. This investigation is able to give a clear image about the proper design of solar dish collectors. To the authors' knowledge, there is no other study which investigates these cavity receivers with different working fluids. It is essential to state that the developed numerical model is validated using experimental results for hemispherical receiver. Furthermore, this study investigates the three cavities in a systematic way for both working fluids and thus, the results of this work can lead to clear and useful conclusions. Emphasis is given on the evaluation of useful heat 
production and pressure drop, using the exergetic efficiency and the overall efficiency. The system is investigated for operation with water up to $90^{\circ} \mathrm{C}$ and with Behran oil up to $300^{\circ} \mathrm{C}$. The operation with water corresponds to low-temperature applications such as space heating, solar cooling and desalination, while the application of thermal oil corresponds to applications for power generation with organic Rankine cycles for instance. The results of this work show the best configuration among the considered cavity receivers for a dish collector.

\section{Experimental Investigation}

The experiments were carried out with the hemispherical cavity at the Renewable Energy Research Center of Tarbiat Modares University, Tehran, Iran $\left(35.68^{\circ} \mathrm{N}\right.$ latitude and $51.42^{\circ} \mathrm{E}$ longitude). The developed setup consists of a parabolic dish concentrator, a hemispherical cavity receiver and a hydraulic circuit system. Table 1 includes the physical parameters of the system and Figure 1 shows the examined solar dish collector with all its components. Figure 2 shows the hemispherical cavity receiver. More specifically, Figure 2a illustrates the coiled copper tubes and Figure $2 b$ the coated cavity receiver. The copper tubes have been selected for its high thermal conductivity of close to $386 \mathrm{~W} / \mathrm{mK}$. Moreover, the selective coating has been used in order to minimize the thermal radiation losses. More specifically, a black chrome $\left(\mathrm{Cr}_{-}-\mathrm{Cr}_{2} \mathrm{O}_{3}\right)$ coating was used which is stable up to $400^{\circ} \mathrm{C}$ [34-35]. The investigated coated cavity receiver of Figure $2 \mathrm{~b}$ was manufactured by Mina Company (Tehran, Iran). Finally, only the aperture was left without insulation and this is the part with the most heat loss. The details of the materials used in building the cavity receiver are given in Table 2 .

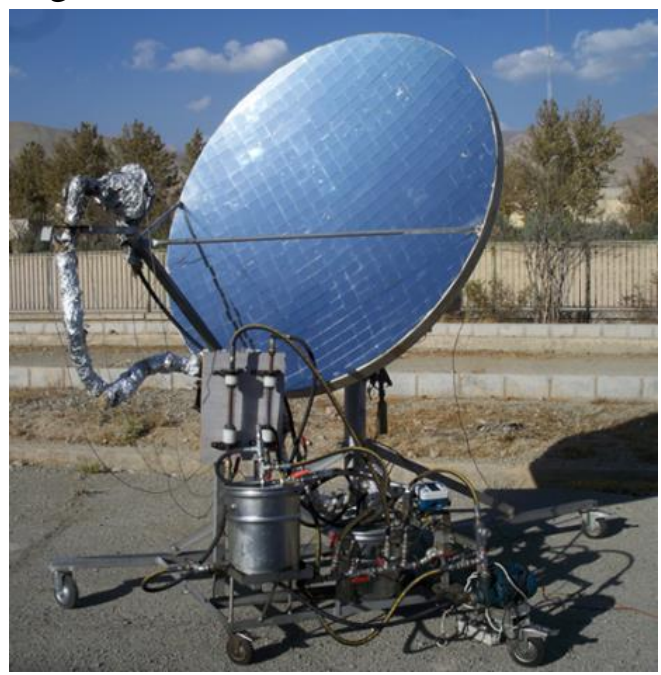

Figure 1. The investigated parabolic dish concentrator with cavity receiver. 


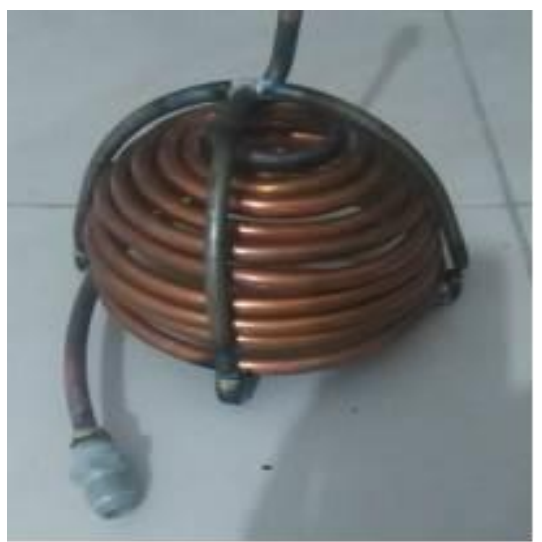

(a)

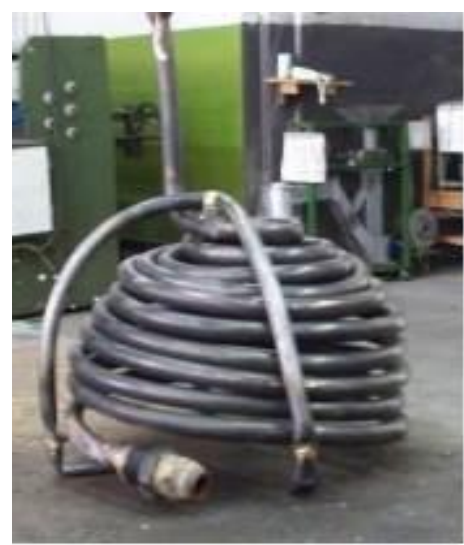

(b)

Figure 2. Hemispherical cavity receiver: a) coiled copper tubes, and b) coated cavity receiver.

Table 1. Parameters of the investigated solar collector in the experimental setup.

\begin{tabular}{ll}
\hline Parameter & Value \\
\hline Concentrator diameter & $1.9 \mathrm{~m}$ \\
Focal distance & $1 \mathrm{~m}$ \\
Rim angle & $50.82^{\circ}$ \\
Collector aperture area & $2.835 \mathrm{~m}^{2}$ \\
Cavity tube outer diameter & $10 \mathrm{~mm}$ \\
Cavity tube inner diameter & $9 \mathrm{~mm}$ \\
Number of cavity coils & 10 \\
Cavity inner diameter & $0.141 \mathrm{~m}$ \\
Cavity outer diameter & $0.161 \mathrm{~m}$ \\
Absorber emittance & 0.1 \\
Absorber absorbance & 0.84 \\
Mirror reflectance & 0.84 \\
Mirror thickness & $3 \mathrm{~mm}$ \\
\hline
\end{tabular}

Table 2. The materials used in building the cavity receiver.

\begin{tabular}{|c|c|c|}
\hline Used Instrument & Properties & Reason \\
\hline \multicolumn{3}{|c|}{ Stage 1} \\
\hline Copper tube & $\begin{array}{l}\text { - Thermal conductivity equal to } 386 \mathrm{~W} / \mathrm{m} \mathrm{K} \\
\text { - High melting point of } 1000^{\circ} \mathrm{C}\end{array}$ & High conductivity \\
\hline \multicolumn{3}{|c|}{ Stage 2} \\
\hline Black chrome coating & $\begin{array}{ll}\text { - } & \text { Emittance equal to } 0.1 \\
\text { - } & \text { Absorbance equal to } 0.84 \\
\text { - } & \text { Stability up to } 400^{\circ} \mathrm{C}\end{array}$ & High absorbance \\
\hline \multicolumn{3}{|c|}{ Stage 3} \\
\hline Mineral wool insulation & $\begin{array}{l}\text { - Mineral wool thickness equal to } 0.02 \mathrm{~m} \\
\text { - Average conductivity equal to } 0.062 \mathrm{~W} / \mathrm{m} \mathrm{K}\end{array}$ & High thermal resistance \\
\hline
\end{tabular}


Another part of the experimental setup was the heat exchanger system. The heat exchanger system included two plate type heat exchangers, an air blower (SIEMENS model: VSRG5), and a blower inverter (LISTED model: SV004IC5-1F). In the heat exchanger system, the gained heat by the investigated cavity receivers was removed by an air blower. Then, the exit oil from the heat exchangers could be injected into the closed hydraulic cycle for pumping, flowing through the cavity receiver, and capturing thermal energy. The plate type heat exchangers were selected because of high efficiency. The blower air velocity was controlled by the blower inverter. Different parts of the heat exchanger system are shown in Figure 3.

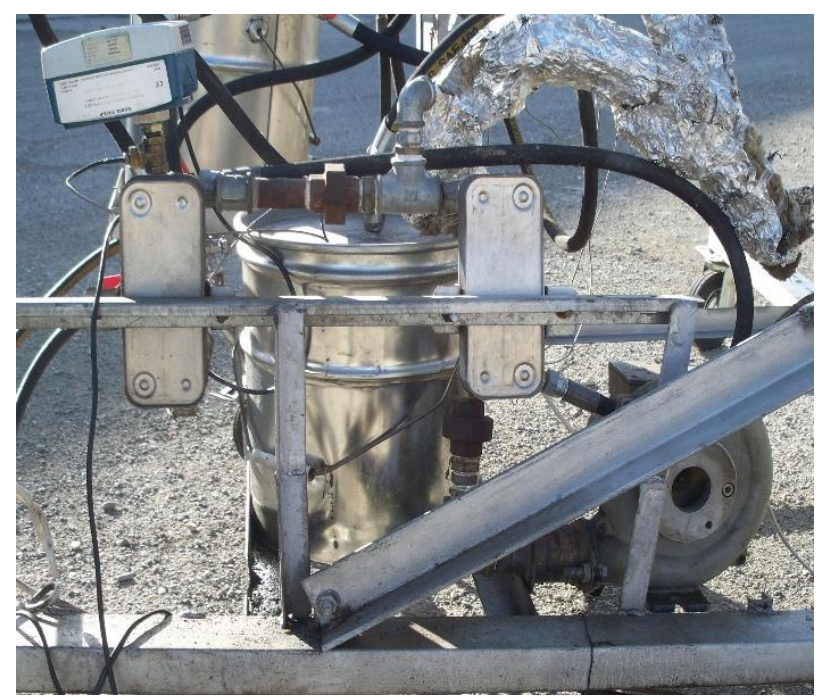

(a)

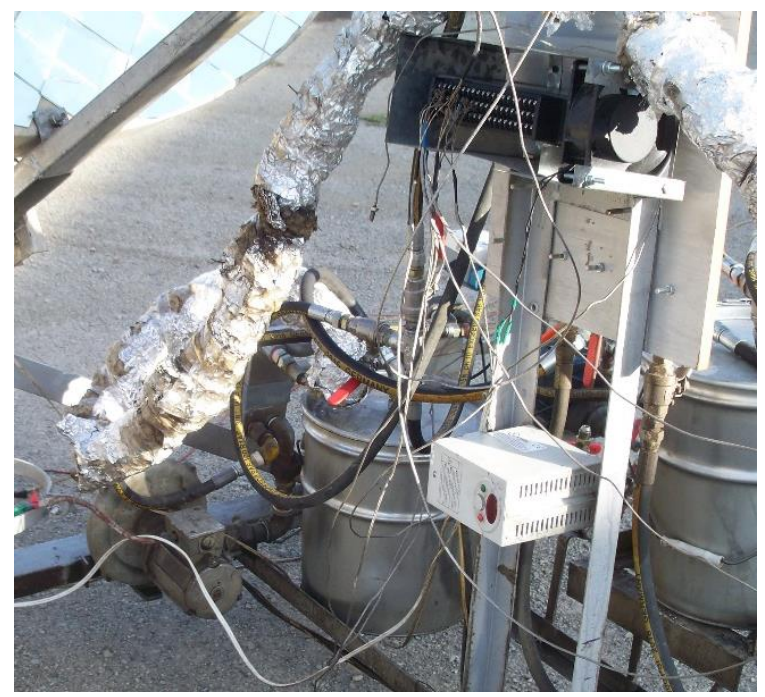

(b)

Figure 3. View of the heat exchanger system's different parts: a) back side of the heat exchangers, b) front side of the heat exchanger system.

The final part of the designed experimental setup was the hydraulic cycle. The hydraulic circuit included an oil pump, valves, a volume flow meter, an inlet tank, and an exit tank. The inlet tank and exit tank each had a 20-liter capacity. The hydraulic system is depicted in Figure 4 with details. 


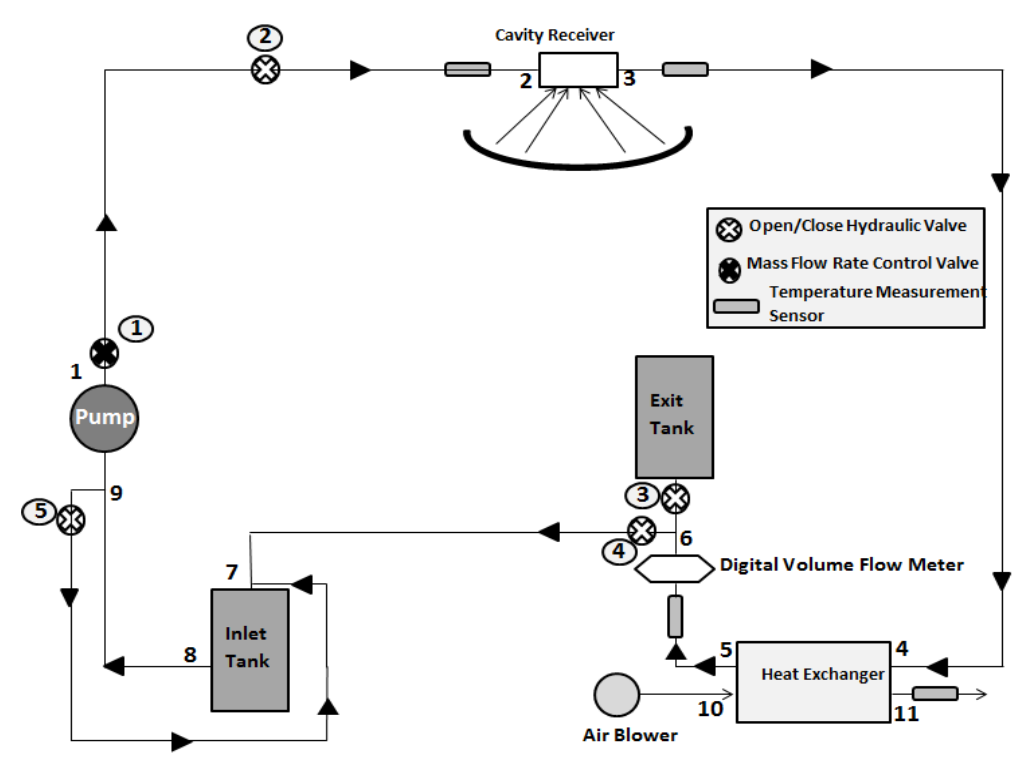

Figure 4. Schematic of the hydraulic circuit.

Thermal oil was selected as the working fluid of the investigated solar system, because of its high heat transfer capacity and low viscosity. Thermal oil is recommended for higher temperature applications such as solar dish concentrator applications [23]. The Behran thermal oil was selected as the solar working fluid in this study. The thermal characteristics of the Behran thermal oil are obtained by Equations (1-4) [36]. Moreover, Appendix A includes information about the thermal properties of this thermal oil.

$$
\begin{gathered}
k_{f}=0.1882-8.304 \times 10^{-5}\left(T_{f}\right) \\
c_{p, f}=0.8132+3.706 \times 10^{-3}\left(T_{f}\right) \\
\rho_{f}=1071.76-0.72\left(T_{f}\right) \\
\operatorname{Pr}=6.73899 \times 10^{21}\left(T_{f}\right)^{-7.7127}
\end{gathered}
$$

\subsection{Instrumentation and measurement system}

During the experimental tests, flow rate, fluid temperature, solar irradiation, and weather conditions (ambient temperature and wind speed) were measured. A volume flow meter (FLUIDWELL model: F016-P) was used for measuring the volumetric flow rate of the solar working fluid. The working fluid temperatures at the inlet and outlet of the cavities, as well as the cavity surface temperatures were measured with K-type thermocouples (Chromel-Alumel). The Omron data logger (model: ZR-RX-45) was used to monitor and store the temperature data. The radiation heat flux was measured by using a Hukseflux pyranometer (model: SR12). Also, the ambient temperature and the wind speed were measured by a K-type thermocouple and an anemometer (CT model: AM-4220), respectively. The accuracy and the ranges of the measuring instruments are given in Table 3 . 
Table 1. Accuracies and ranges of the measuring instruments.

\begin{tabular}{llll}
\hline Instrument & Accuracy & Range & \% error \\
\hline K-type thermocouples & $\pm 0.55^{\circ} \mathrm{C}$ & $0-800^{\circ} \mathrm{C}$ & 0.25 \\
Solar power meter & $\pm 0.1 \mathrm{~W} / \mathrm{m}^{2}$ & $0-2000 \mathrm{~W} / \mathrm{m}^{2}$ & 0.25 \\
Anemometer & $\pm 0.2 \mathrm{~m} / \mathrm{s}$ & 0.9 to $35.0 \mathrm{~m} / \mathrm{s}$ & 10 \\
Volume flow meter & $\pm 0.05 \mathrm{~mA}$ & $0-20 \mathrm{~mA}$ & 1 \\
\hline
\end{tabular}

\section{Simulation and Methodology}

In this work, three different cavity receivers are examined using water and thermal oil as working fluids. A hemispherical, a cubical and a cylindrical cavity receiver were numerically modeled, as they are presented in Figure 5. A schematic of the investigated hemispherical, cubical and cylindrical cavity receivers is displayed in Figures 5a, 5b, and 5c, respectively. All cavities have the same tube diameter. The detailed dimensions of the three investigated cavity receivers, as well as modeling parameters, are given in Table 4. Note that the numerical methodology for the cubical and the cylindrical receiver was presented in detail in Refs. [14] and [25] respectively, using thermal oil. In this study, the numerical thermal modeling of the hemispherical cavity receiver is investigated in detail. Finally, a comparison of the three types of cavity receivers is given using energy and exergy criteria. Water and thermal oil are used as working fluids in the numerical investigation. Note that the developed thermal model is validated using the obtained experimental results and the validation results are given in Section 4.1.

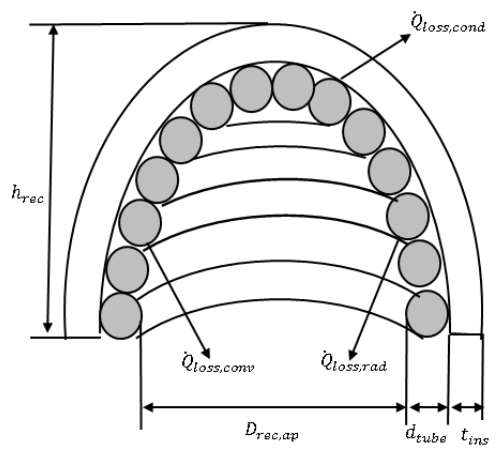

(a)

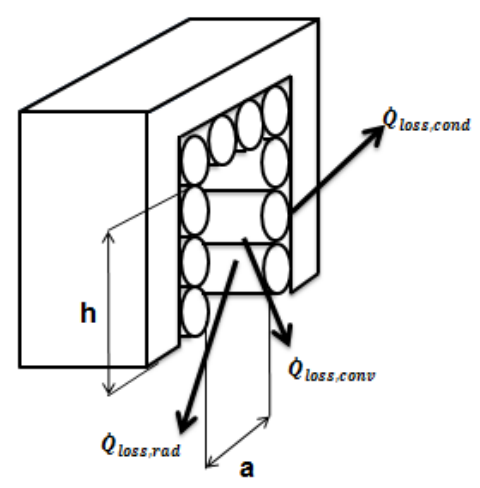

(b)

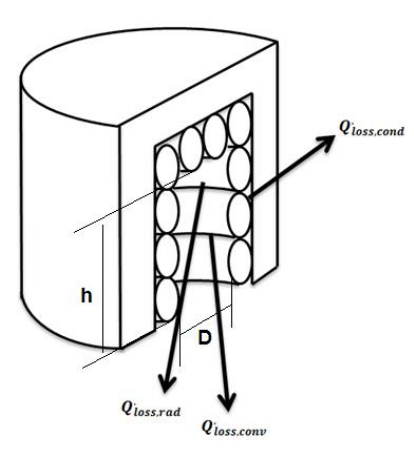

(c)

Figure 5. A schematic of a) the investigated hemispherical cavity receiver, b) the cubical cavity receiver and c) the cylindrical cavity receiver. 
Table 4: Dimensions and parameters used in the numerical modeling of the solar collector with cavity receiver.

\begin{tabular}{|c|c|cc|}
\hline & $\begin{array}{c}\text { Validation of } \\
\text { experimental results }\end{array}$ & \multicolumn{3}{|c|}{ Comparison of three different cavity } \\
receivers
\end{tabular}

\subsection{Energy Analysis of the collector}

Three cavity receivers are investigated in this study. The working fluid (water or thermal oil) flows from the bottom to the top of each of the investigated cavity receivers, because of better performance in this direction. According to Refs [37-38], the parameters that are used in the determination of the receiver temperature can be separated into geometry dependent and temperature dependent parameters. Moreover, it is important to state that the optical analysis was performed with SolTrace, as described below. The most important parameters which depend on temperature are heat losses. Heat losses are separated into convection, conduction and radiation heat loss.

\subsubsection{Optical Modeling of the cavities}

The optical analysis is conducted using the commercial software, SolTrace [39]. This tool uses the Monte Carlo ray tracing method in order to perform the optical analysis of the collector. This method is based on the utilization of a great number of rays that have to be traced in order to simulate the real phenomenon of the reflection. The absorbed solar energy over each coil of the 
absorber is found separately and finally, the total absorbed heat rate can be found by adding the absorbed heat rate of each coil. Table 5 gives more detail about the optical analysis of the cavities. Figure 6 is an image from the SolTrace environment showing the hemispherical cavity analysis as an example. Note that this methodology has been applied to all the considered cavities.

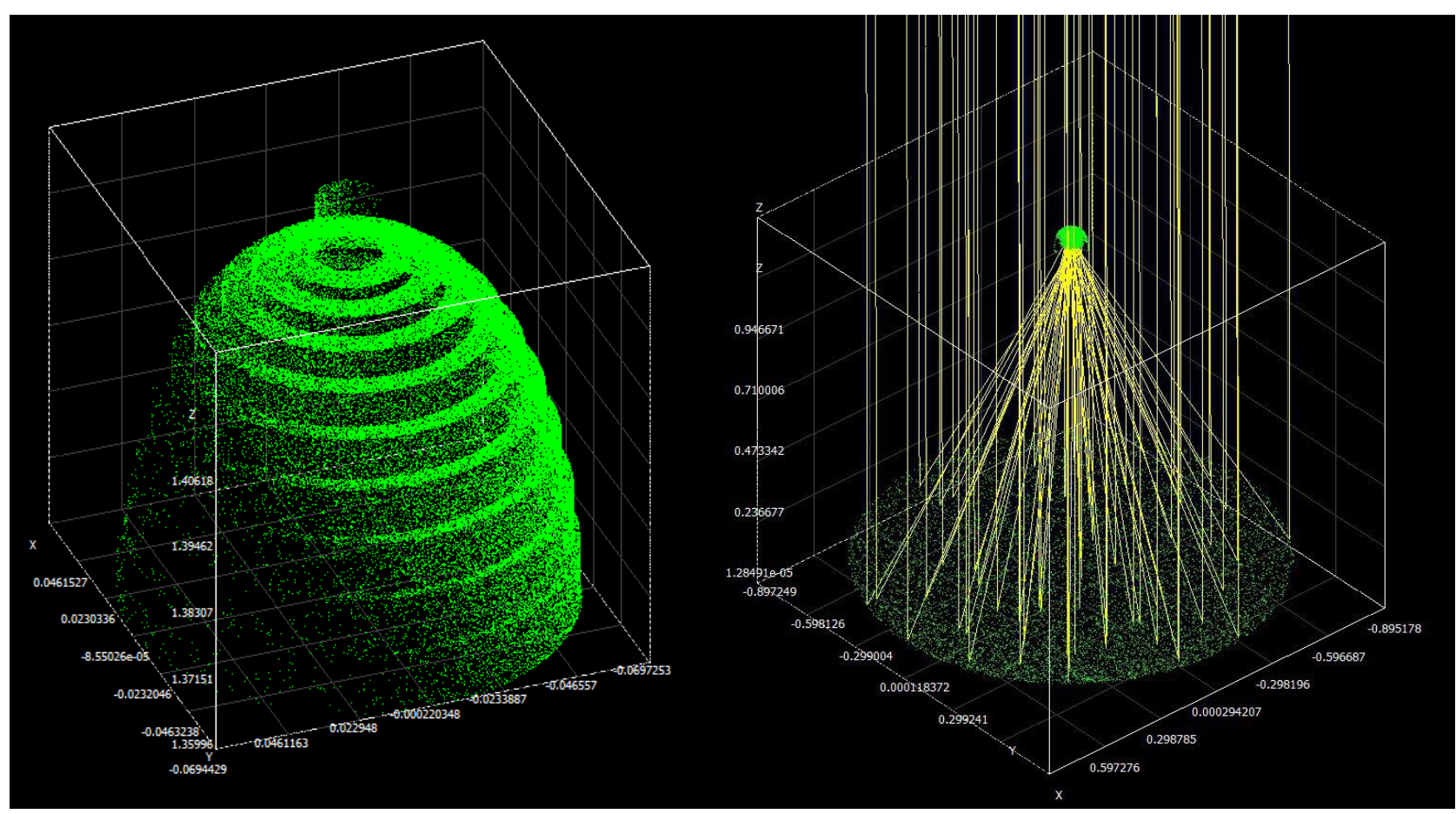

(a)

(b)

Figure 6. Heat flux distribution for a) each coil of the investigated hemispherical cavity receiver, b) the investigated solar dish system.

Table 5. SolTrace modeling parameters.

\begin{tabular}{lc}
\hline Parameter & Value \\
\hline The reflectance of the cavity walls & 0.15 \\
Number of ray intersections & 100000 \\
The optical errors & $10 \mathrm{mrad}$ \\
The tracking error & $1^{\circ}$ \\
The half-angle width & $4.65 \mathrm{mrad}$ \\
The sun-shape & Pillbox \\
\hline
\end{tabular}

\subsubsection{Thermal modeling of the collector}

The developed thermal model is based on the determination of the cavity heat losses which include radiation, convection and conduction parts. The cavity is insulated with mineral wool. Figure 7 shows the heat losses from the hemispherical receiver, as an example. Consider the most basic heat loss analysis described in the equations below. The net useful heat transfer rate $\left(\dot{Q}_{n e t}\right)$ at the receiver is calculated using Equations (5-6). Equation 5 is the general energy 
balance on the absorber and Equation 6 is the absorbed energy definition. Equation 7 gives the calculation of the solar energy on the collector aperture. Note that in this section, a basic model is described for clarification purposes. A more detailed model, based on the equations in this section, is presented in Section 3.1.3.

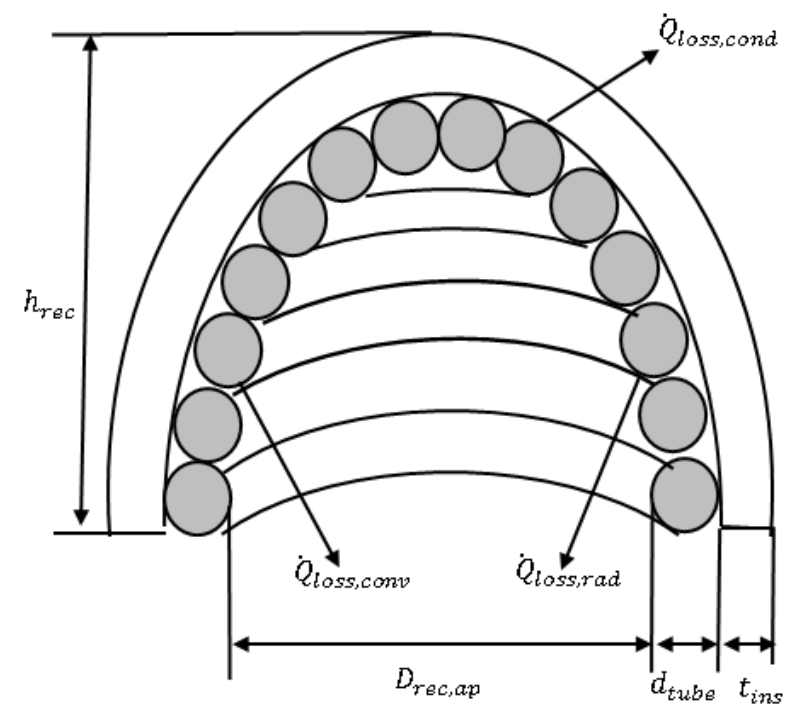

Figure 1. Schematic of the investigated hemispherical cavity receiver.

$$
\begin{gathered}
\dot{Q}_{n e t}=\dot{Q}^{*}-\dot{Q}_{\text {loss,cond }}-\dot{Q}_{\text {loss, rad }}-\dot{Q}_{\text {loss, conv }} \\
\dot{Q}^{*}=\eta_{\text {optical }} \cdot \eta_{\text {refl }} \cdot \dot{Q}_{\text {solar }} \\
\dot{Q}_{\text {solar }}=I_{\text {sun }} \cdot \pi \cdot \frac{D_{\text {conc }}^{2}}{4}
\end{gathered}
$$

$\dot{Q}^{*}$ is the total solar heat transfer rate available at the cavity receiver, $\eta_{\text {optical }}$ is the optical efficiency of the system (see equation 8), $\eta_{\text {refl }}$ is the dish reflectivity which is chosen as $84 \%$, $\dot{Q}_{\text {solar }}$ is the solar heat transfer rate available at the dish concentrator, $I_{\text {sun }}$ is the average solar beam irradiation in Tehran and $D_{\text {conc }}$ is the dish aperture diameter. Moreover, $\dot{Q}_{\text {loss,cond }}$, $\dot{Q}_{\text {loss,rad }}$ and $\dot{Q}_{\text {loss,conv }}$ are the conduction, radiation and convection heat losses of the receiver respectively. The ratio of the absorbed heat at the cavity $\left(\dot{Q}^{*}\right)$ to the total solar heat coming from the dish concentrator is the optical efficiency of the receiver (Equation 8). $\dot{Q}^{*}$ can be calculated using the SolTrace software, as previously mentioned. The optical efficiency of each collector analyzed in SolTrace is therefore shown in Table 6 . The hemispherical cavity receiver is shown to have the maximum optical efficiency. This is due to manufacturing constraints, as shown in Figure 2, which creates an open cavity top. Furthermore, note that the absorptivity is already accounted for in the SolTrace model. 


$$
\eta_{\text {optical }}=\frac{\dot{Q}^{*}}{\eta_{\text {refl }} \cdot \dot{Q}_{\text {solar }}}
$$

Table 6: Optical efficiency of the collector with cavity receivers as calculated with SolTrace.

\begin{tabular}{|l|c|ccc|}
\hline & $\begin{array}{c}\text { Validation of } \\
\text { experimental } \\
\text { results }\end{array}$ & \multicolumn{2}{c|}{ Comparison of three different cavity receivers } \\
\hline & Hemispherical & Cubical & Cylindrical & Hemispherical \\
\hline Concentrator diameter $(\mathrm{m})$ & 1.9 & 1.8 & 1.8 & 1.8 \\
\hline Focal distance $(\mathrm{m})$ & 1 & 1.351 & 1.351 & 1.351 \\
\hline Paraboloid rim angle & $50.82^{\circ}$ & $36.84^{\circ}$ & $36.84^{\circ}$ & $36.84^{\circ}$ \\
\hline Collector aperture area $\left(\mathrm{m}^{2}\right)$ & 2.835 & 2.545 & 2.545 & 2.545 \\
\hline Optical efficiency & $\mathbf{0 . 9 0}$ & $\mathbf{0 . 9 4}$ & $\mathbf{0 . 9 3}$ & $\mathbf{0 . 9 5}$ \\
\hline
\end{tabular}

Furthermore, the receiver thermal efficiency $\left(\eta_{t h}\right)$ is defined as the ratio of the receiver net heat transfer rate to the incoming solar heat transfer rate of the cavity receiver:

$$
\eta_{t h}=\frac{\dot{Q}_{n e t}}{\dot{Q}_{\text {solar }}}
$$

\subsubsection{Conduction heat loss}

In steady-state conditions, the overall thermal resistance of the conduction and the external convection $\left(R_{\text {total }}\right)$ is calculated according to Equation 10. Using this parameter, the overall heat loss rate due to the conduction and external convection can be calculated with Equation 10:

$$
\dot{Q}_{\text {loss }, \text { cond }}=\frac{A_{\text {rec }} \cdot\left(T_{s, \text { Ave }}-T_{\infty}\right)}{R_{\text {total }}}=\frac{A_{\text {rec }} \cdot\left(T_{s, \text { Ave }}-T_{\infty}\right)}{1 / h_{\text {outer }}+t_{\text {ins }} / k_{\text {ins }}}
$$

The insulation of the cavity has $2 \mathrm{~cm}$ thickness, its thermal conductivity is about $0.062 \mathrm{~W} / \mathrm{mK}$ and its emittance is about 0.2 [40]. Note that the radiation heat losses of the external insulation surfaces are neglected.

The external convection heat transfer coefficient of air over the investigated cavity receivers is calculated by assuming simultaneous natural and forced convection conditions. The Nusselt number equation for forced convection of air over the receiver is given as [41]:

$$
N u_{\text {forced }}=2+\left[0.4 \cdot R e^{1 / 2}+0.06 \cdot R e^{2 / 3}\right] \cdot \operatorname{Pr}^{0.4} \cdot\left(\frac{\mu_{\infty}}{\mu_{s}}\right)^{1 / 4}
$$

with

$$
R e=\frac{\rho \cdot V_{\text {wind }} \cdot D_{\text {rec,outer }}}{\mu}
$$




$$
D_{\text {rec }, \text { outer }}=D_{\text {rec,ap }}+2 \cdot\left(d_{\text {tube }}+t_{\text {ins }}\right)
$$

$D_{r e c, a p}$ is the diameter of the aperture of the cavity receiver, $d_{\text {tube }}$ is the receiver tube diameter and $t_{i n s}$ is the thickness of the insulation layer. The fluid thermal properties in Equations 11 and 12 are calculated at the ambient temperature, $T_{\infty}$, except for $\mu_{s}$, which is evaluated at the surface temperature, $T_{s}$. The Nusselt number for natural convection is calculated as [41]:

$$
N u_{\text {natural }}=2+\frac{0.589 R a_{D}^{1 / 4}}{\left[1+(0.469 / P r)^{9 / 16}\right]^{4 / 9}}
$$

The fluid thermal properties are calculated at the temperature, $T_{f}=\frac{T_{s}+T_{\infty}}{2}$. The combined Nusselt number, which includes both natural and forced convection, is calculated as [41]:

$$
N u_{\text {combined }}=\left(N u_{\text {forced }}^{3.5}+N u_{\text {natural }}^{3.5}\right)^{\frac{1}{3.5}}
$$

Consequently, the convection heat transfer coefficient is calculated as:

$$
h_{\text {outer }}=\frac{k_{\infty} \cdot N u_{\text {combined }}}{D_{\text {rec,outer }}}
$$

\subsubsection{Radiation heat loss}

The radiation Nusselt number $\left(N u_{r a d}\right)$ for the hemispherical cavity receiver can be estimated according to the following equations [42]. The emittance of the receiver tube is assumed to be 0.1 for the black chrome.

$$
\begin{gathered}
N u_{\text {rad }}=9.650 G r_{D}^{0.068}(1+\cos \theta)^{0.001}(\varepsilon)^{0.546}\left(N_{\text {rc }}\right)^{0.478}[1 \\
\left.-\left(T_{R}\right)^{4}\right]^{8.768}\left(\frac{D_{\text {rec }, \text { ap }}}{D_{\text {rec }, \text { outer }}}\right)^{0.493}
\end{gathered}
$$

with

$$
\begin{gathered}
N_{r c}=\frac{\sigma \cdot T_{s}^{4} \cdot\left(\frac{D_{\text {rec,outer }}}{2}\right)}{\left(T_{s}-T_{\infty}\right) k_{a}} \\
T_{R}=\frac{T_{\infty}}{T_{s}} \\
G r_{D}=\frac{g \cdot \beta \cdot\left(T_{s}-T_{\infty}\right) \cdot D_{\text {rec }, \text { outer }}{ }^{3}}{\vartheta^{2}} \\
h_{\text {rad }}=\frac{N u_{\text {rad }} \cdot k_{a}}{D_{\text {rec }, \text { outer }}}
\end{gathered}
$$

The total radiation heat loss rate from the receiver aperture can be determined as:

$$
\dot{Q}_{\text {loss }, \text { rad }}=h_{\text {rad }} \cdot \mathrm{A}_{\text {rec }} \cdot\left(T_{s}-T_{\infty}\right)
$$




\subsubsection{Convection heat loss}

The internal convection heat loss has to take into account both the natural convection and the forced convection mechanisms [43]:

$$
\begin{aligned}
h_{\text {forced }} & =4.22 \cdot\left(V_{\text {wind }}{ }^{0.805}\right) \\
h_{\text {natural }} & =1.45 \cdot\left(T_{S}-T_{\infty}\right)^{0.333} \\
h_{\text {total }} & =h_{\text {forced }}+h_{\text {natural }}
\end{aligned}
$$

The thermal properties of the air are evaluated at the ambient temperature $\left(T_{\infty}\right)$. The total convection heat loss rate of the receiver is calculated as:

$$
\dot{Q}_{\text {loss,conv }}=h_{\text {total }} \cdot A_{\text {rec }} \cdot\left(T_{s}-T_{\infty}\right)
$$

\subsubsection{Numerical methods for receiver modeling}

The approach discussed above can be used to do basic modeling of a solar receiver. It should be noted, however, that in this work, a more detailed modeling approach is taken in which a number of elements are considered. Each receiver coil is considered as an element with a specific surface temperature and net heat transfer rate. The developed numerical model is described in detail below.

The optical analysis is performed with SolTrace, while the thermal analysis of the developed thermal model is conducted using Maple software. Note that the optical efficiencies, as shown in Table 5, cannot be used in the numerical analysis since each coil of each receiver has a different solar heat transfer rate $\left(Q_{n}^{*}\right)$ available (as calculated with SolTrace). The receiver surface temperature $\left(T_{s, n}\right)$ and the useful heat transfer rate $\left(\dot{Q}_{n e t, n}\right)$ at the different elements of the tube are calculated by solving Equations (27) and (32) with the Newton-Raphson Method [37], by assuming mean surface temperature of $200^{\circ} \mathrm{C}$ as an initial value for the first iteration:

$$
\dot{Q}_{n e t, n}=\frac{\left(T_{s, n}-\sum_{i=1}^{n-1}\left(\frac{\dot{Q}_{n e t, i}}{\dot{m} c_{p 0}}\right)-T_{\text {inlet }, 0}\right)}{\left(\frac{1}{h_{\text {inner }} A_{n}}+\frac{1}{2 \dot{m} c_{p 0}}\right)}
$$

The Nusselt number of the internal working fluid flow is estimated as:

$$
N u_{\text {inner }}=\frac{\left(\frac{f_{r}}{8}\right) \cdot R e \cdot \operatorname{Pr}}{1+12.8 \cdot \sqrt{\frac{f_{r}}{8}} \cdot\left(\operatorname{Pr}^{0.68}-1\right)}
$$

The friction factor $\left(f_{r}\right)$ is calculated as:

$$
f_{r}=(0.79 \ln R e-1.64)^{-2}
$$


Moreover, the inner heat transfer coefficient is calculated as:

$$
h_{\text {inner }}=\frac{N u_{\text {inner }} \cdot k_{f}}{d_{\text {tube }}}
$$

The net heat transfer rate can be calculated using the following equations:

$$
\begin{gathered}
\dot{Q}_{n e t, n}=\dot{Q}_{n}^{*}-\dot{Q}_{\text {loss }, \text { rad }, n}-\dot{Q}_{\text {loss }, \text { conv }, n}-\dot{Q}_{\text {loss }, \text { cond }, n} \\
\dot{Q}_{n e t, n}=\dot{Q}_{n}^{*}{ }_{n}-A_{n} \varepsilon_{n} \sigma\left(T_{s, n}{ }^{4}\right)+A_{n} \sum_{j=1}^{N} F_{n-j} \varepsilon_{j} \sigma\left(T_{s, n}{ }^{4}\right)-A_{n} \varepsilon_{n} \sigma F_{n-\infty} T_{\infty}^{4} \\
\quad-A_{n}\left(m_{2} T_{s, n}+c_{2}\right)-\frac{A_{n}}{R_{\text {cond }}}\left(T_{s, n}-T_{\infty}\right)
\end{gathered}
$$

Finally, after calculation of the useful heat transfer rate $\left(\dot{Q}_{n e t, n}\right)$ at the different elements of the tube, the thermal efficiency of the investigated cavity receiver is calculated as following:

$$
\eta_{\text {th }}=\sum_{n=1}^{N} \frac{\dot{Q}_{\text {net }, n}}{\dot{Q}_{\text {solar }}}
$$

It is important to emphasize that each coil of the receiver has been assumed to be a different element in the present modeling.

\subsection{Exergy analysis}

An exergy analysis is a very important tool for the investigation of energy systems [44]. An exergy analysis is especially vital for concentrating collectors, as they are usually coupled to power cycles for power generation. Practically, the exergy analysis takes into consideration both the amount of the useful heat production and the operating temperature in order to evaluate the possible margin for work production.

The maximum exergy flow of the incident solar beam irradiation can be estimated using the Petela model [45]:

$$
\eta_{p}=1-\frac{4}{3} \cdot \frac{T_{\infty}}{3 T_{\text {sun }}}+\frac{1}{3} \cdot\left(\frac{T_{\infty}}{T_{\text {sun }}}\right)^{4}
$$

The sun temperature $T_{\text {sun }}$ was selected to be $5800 \mathrm{~K}$. The exergy of the solar irradiation can be written as [46]:

$$
\sum \dot{E}_{\text {in,rec }}=\eta_{p} \cdot I_{\text {solar }} \cdot A_{\text {conc }}
$$

The useful exergy production of the collector is calculated as [46]:

$$
\sum \dot{E}_{\text {gain }}=\dot{m} \cdot C_{p} \cdot\left(T_{\text {outlet }}-T_{\text {inlet }}-T_{\infty} \ln \left(\frac{T_{\text {outlet }}}{T_{\text {inlet }}}\right)\right)-\frac{T_{\infty}}{T_{f}} \frac{\dot{m} \Delta P}{\rho}
$$

The exergetic efficiency of the collector is the ratio of the useful exergy production to the exergy input from the sun, as Equation 37 indicates: 


$$
\eta_{\text {exergy }}=\frac{\sum \dot{E}_{\text {gained }}}{\sum \dot{E}_{\text {in }, \text { rec }}}
$$

\subsection{Pressure drop - Overall efficiency}

The pressure drop calculation is very important in a cavity receiver because of the existence of curvature in the tubes. Moreover, the pressure drop is directly connected with the pumping power demand which influences the operating cost of the system. The total pressure drop of the absorber can be estimated using Equations (38) and (39) [47-48]:

$$
\begin{aligned}
\Delta P & =\frac{\rho \cdot\left(V^{2}{ }_{A v g}\right)}{2} \cdot\left(f_{r} \cdot \frac{L}{d}+\sum_{y} K_{y}\right) \\
\Delta P & =\frac{8 \cdot \dot{m}^{2}}{\rho \cdot \pi^{2} \cdot d^{4}} \cdot\left(f_{r} \cdot \frac{L}{d}+\sum_{y} K_{y}\right)
\end{aligned}
$$

Moreover, the equivalent thermal output $\left(\dot{Q}_{e q}\right)$ is defined as follows:

$$
\begin{gathered}
\dot{W}_{\text {Pump }}=\frac{\Delta P \cdot \dot{m}}{\rho} \\
\dot{Q}_{e q}=\left(\dot{Q}_{n e t}-\frac{\dot{W}_{\text {Pump }}}{\eta_{e l}}\right)
\end{gathered}
$$

Where $\eta_{e l}$ will be assumed equal to 0.33 for the investigated system [49]. This value is practically the mean electrical efficiency of the grid. The overall efficiency is defined using the equivalent thermal output and the solar energy input:

$$
\eta_{\text {overall }}=\frac{\dot{Q}_{e q}}{\dot{Q}_{\text {solar }}}
$$

\section{Results and Discussion}

\subsection{Thermal Model Validation}

The first part of the present analysis is a validation, which is the comparison of the obtained numerical results with the respective experimental results of the $28^{\text {th }}$ of September, 2016. Table shows this comparison. Note that the real ambient conditions were used in the numerical model and the obtained numerical results were compared with the respective experimental measurements. The volumetric flow rate was $10 \mathrm{ml} / \mathrm{s}$ in the experimental process. The most important parameter of the collector is the thermal efficiency, as shown in table 7. The deviation ranges from $0.03 \%$ up to $12.06 \%$. The mean deviation is $3.68 \%$, which validates the developed model. 
Table 7. Validation of the developed thermal model with experimental results using the hemispherical cavity receiver with thermal oil.

\begin{tabular}{cccccccccccc}
\hline $\begin{array}{c}\text { Time } \\
(\mathbf{h})\end{array}$ & $\mathbf{T}_{\text {in }}\left({ }^{\circ} \mathbf{C}\right)$ & $\begin{array}{c}\mathbf{T}_{\text {out }} \\
\left({ }^{\circ} \mathbf{C}\right)\end{array}$ & $\begin{array}{c}\mathbf{I}_{\text {sun }} \\
\left(\mathbf{W}^{2} \mathbf{m}\right)\end{array}$ & $\begin{array}{c}\mathbf{T}_{\text {amb }} \\
\left({ }^{\circ} \mathbf{C}\right)\end{array}$ & $\begin{array}{c}\mathbf{V}_{\text {wind }} \\
(\mathbf{m} / \mathbf{s})\end{array}$ & $\begin{array}{c}\mathbf{V} \\
(\mathbf{m l} / \mathbf{s})\end{array}$ & $\begin{array}{c}\text { Experimental } \\
\mathbf{Q}_{\text {net }} \\
(\mathbf{W})\end{array}$ & $\boldsymbol{\eta}_{\text {th }}$ & $\begin{array}{c}\text { Numerical } \\
\mathbf{Q}_{\text {net }}\end{array}$ & $\boldsymbol{\eta}_{\text {th }}$ & Deviation \\
\hline $9: 30$ & 41.10 & 118.10 & 752.82 & 26.9 & 1.2 & 10.0 & 1335.25 & $62.59 \%$ & 1533.460 & $68.00 \%$ & $8.34 \%$ \\
$10: 00$ & 40.00 & 120.40 & 774.27 & 27.8 & 0.5 & 10.0 & 1394.94 & $63.57 \%$ & 1579.267 & $68.38 \%$ & $7.02 \%$ \\
$10: 30$ & 51.23 & 135.89 & 790.79 & 28.0 & 1.3 & 10.0 & 1478.96 & $66.00 \%$ & 1603.834 & $67.99 \%$ & $2.93 \%$ \\
$11: 00$ & 46.38 & 133.82 & 805.02 & 29.0 & 0.8 & 10.0 & 1530.17 & $67.07 \%$ & 1636.206 & $68.14 \%$ & $1.56 \%$ \\
$11: 15$ & 47.35 & 137.06 & 824.22 & 29.0 & 1.2 & 10.0 & 1566.74 & $67.08 \%$ & 1672.577 & $68.03 \%$ & $1.40 \%$ \\
$11: 45$ & 43.77 & 137.26 & 849.04 & 31.3 & 1.0 & 10.0 & 1637.74 & $68.07 \%$ & 1724.448 & $68.09 \%$ & $0.03 \%$ \\
$12: 30$ & 42.27 & 137.75 & 859.22 & 31.6 & 1.6 & 10.0 & 1656.08 & $68.01 \%$ & 1743.750 & $68.03 \%$ & $0.03 \%$ \\
$13: 00$ & 43.20 & 135.43 & 841.63 & 31.5 & 1.4 & 10.0 & 1615.43 & $67.73 \%$ & 1709.131 & $68.08 \%$ & $0.51 \%$ \\
$13: 30$ & 46.10 & 136.73 & 833.46 & 31.0 & 0.5 & 10.0 & 1591.46 & $67.38 \%$ & 1694.192 & $68.14 \%$ & $1.12 \%$ \\
$13: 45$ & 47.86 & 135.65 & 810.56 & 31.0 & 2.1 & 10.0 & 1542.19 & $67.14 \%$ & 1643.844 & $67.99 \%$ & $1.25 \%$ \\
$14: 00$ & 56.00 & 134.30 & 774.60 & 30.0 & 0.6 & 10.0 & 1375.60 & $62.67 \%$ & 1571.469 & $68.01 \%$ & $7.86 \%$ \\
$14: 30$ & 46.80 & 118.00 & 728.86 & 30.0 & 2.2 & 10.0 & 1237.66 & $59.92 \%$ & 1481.424 & $68.14 \%$ & $12.06 \%$ \\
\hline
\end{tabular}

\subsection{Numerical Modeling Comparison}

The solar dish collector is further investigated for operation with thermal oil and water for three different cavities. The simulation is performed with the developed thermal model which is validated according to the results of Section 4.1. Inlet temperatures from $40^{\circ} \mathrm{C}$ up to $90^{\circ} \mathrm{C}$ are considered for water, while temperatures from $40^{\circ} \mathrm{C}$ up to $300^{\circ} \mathrm{C}$ are considered for the thermal oil.

\subsubsection{Results for operation with water}

In this section, results show the collector performance with water. Figures 8-13 give the obtained results for the three different cavities. Note that the results were obtained for a direct normal solar irradiance of $800 \mathrm{~W} / \mathrm{m}^{2}$ and a flow rate of $100 \mathrm{ml} / \mathrm{s}$, as shown in Table 4 . Figure 8 depicts the thermal efficiency and Figure 9 the useful heat production. The curves of these figures have a similar trend. The worst performance is achieved with the cylindrical cavity receiver, while the best performance is achieved with the cubical cavity receiver at low inlet temperatures and the hemispherical cavity receiver at higher inlet temperatures. More specifically, at temperatures higher than $335 \mathrm{~K}$, the hemispherical cavity receiver performs better than the cubical cavity receiver. Results show that the thermal efficiency reduces with an increase in inlet temperature. Note that the produced useful heat transfer rate is in the order of $1500 \mathrm{~W}$ with a thermal efficiency that ranges from $59 \%$ to $70 \%$.

The pressure drop and the pumping power are shown in Figures 10 and 11, respectively. The cubical cavity has the highest pressure drop, followed by the cylindrical and the hemispherical cavities. More specifically, the cubical cavity leads to a pressure drop of $32 \mathrm{kPa}$, the cylindrical cavity to a pressure drop of $22 \mathrm{kPa}$ and the hemispherical cavity to a pressure drop of $5 \mathrm{kPa}$. It is also important to state that the pressure drop decreases slightly as the temperature increases. The 
obtained pressure drop values are relatively high but the pumping work is generally low, as Figure 11 indicates. More specifically, the pumping power for the cubical cavity is close to 3.2 $\mathrm{W}$, close to $2.2 \mathrm{~W}$ for the cylindrical cavity and close to $0.5 \mathrm{~W}$ for the hemispherical cavity. These values are extremely low compared to the $1500 \mathrm{~W}$ of useful heat production, which shows that the pumping power is relatively insignificant.

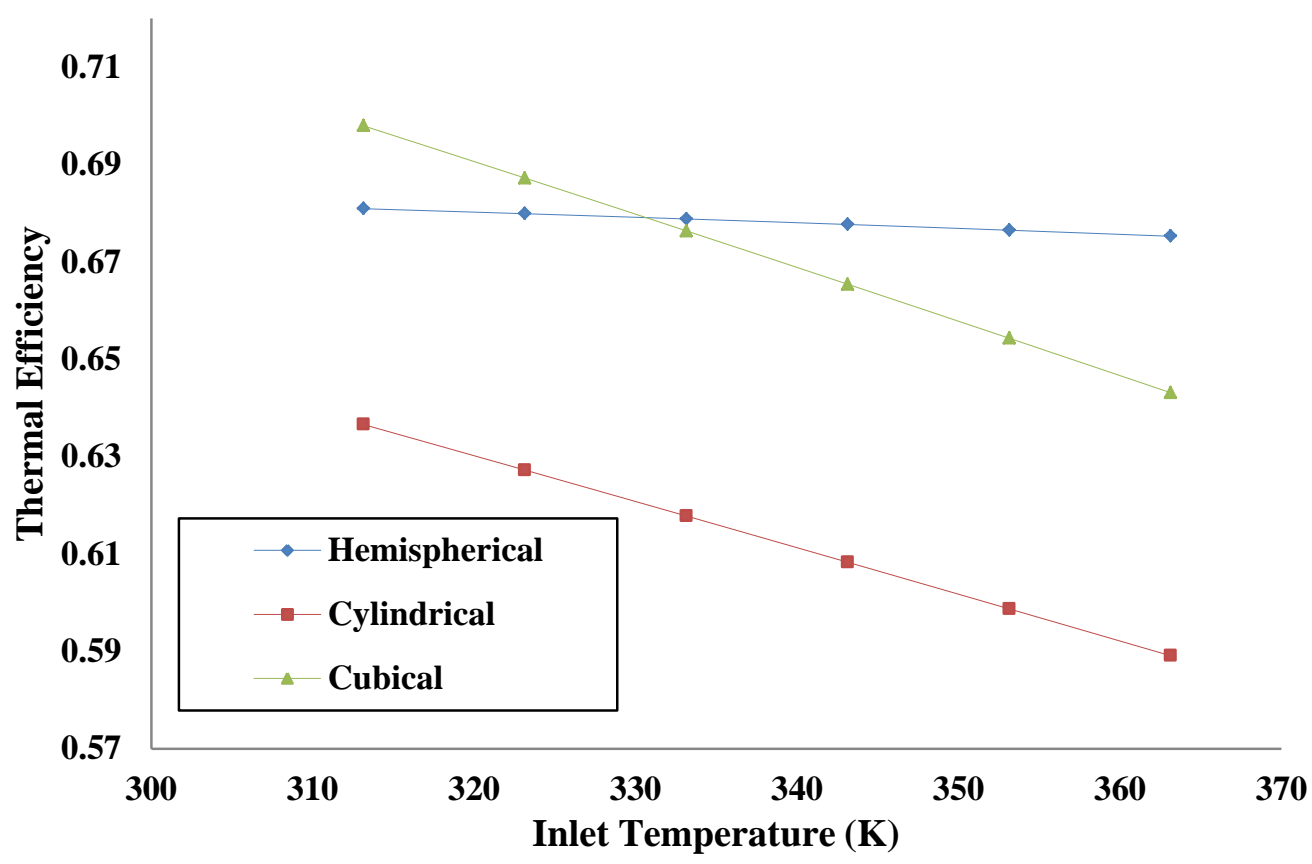

Figure 8. Thermal efficiency of the cavity receivers with water.

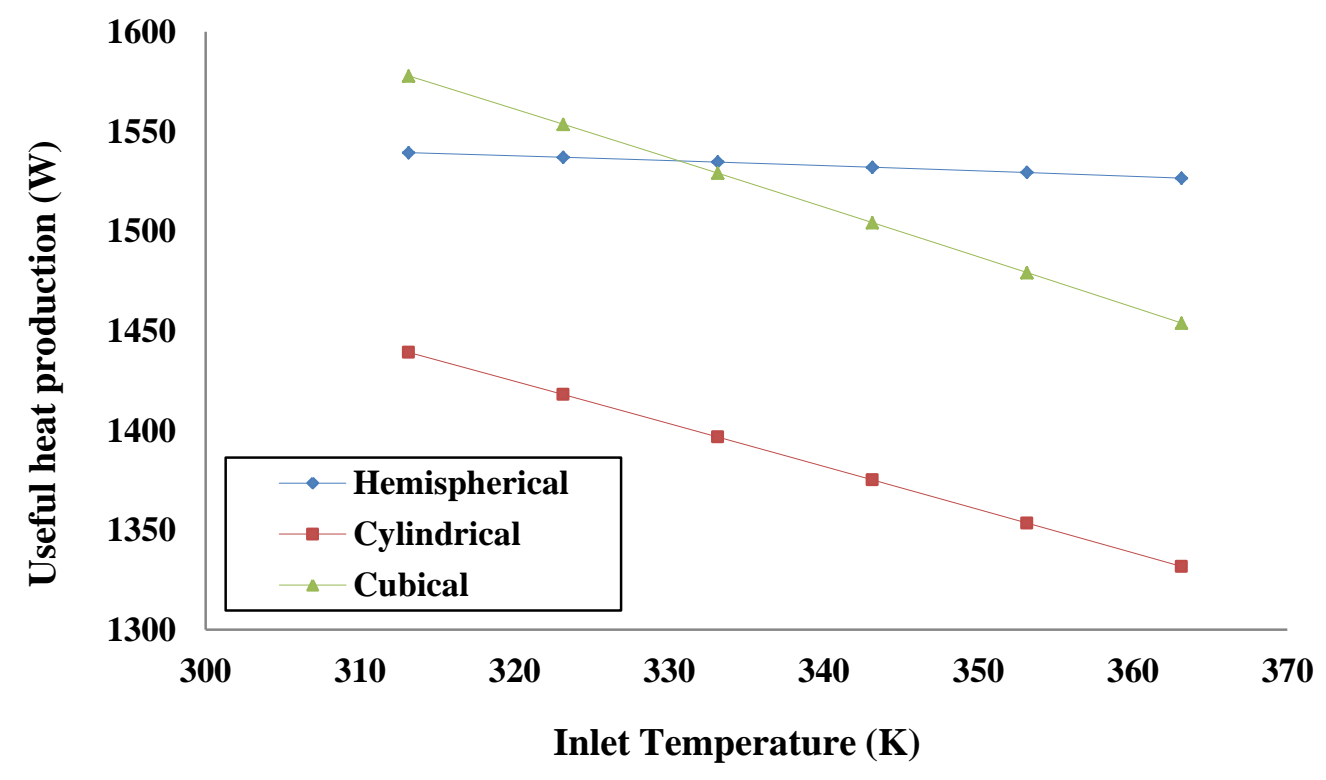

Figure 9. Useful heat production of the cavity receivers with water. 


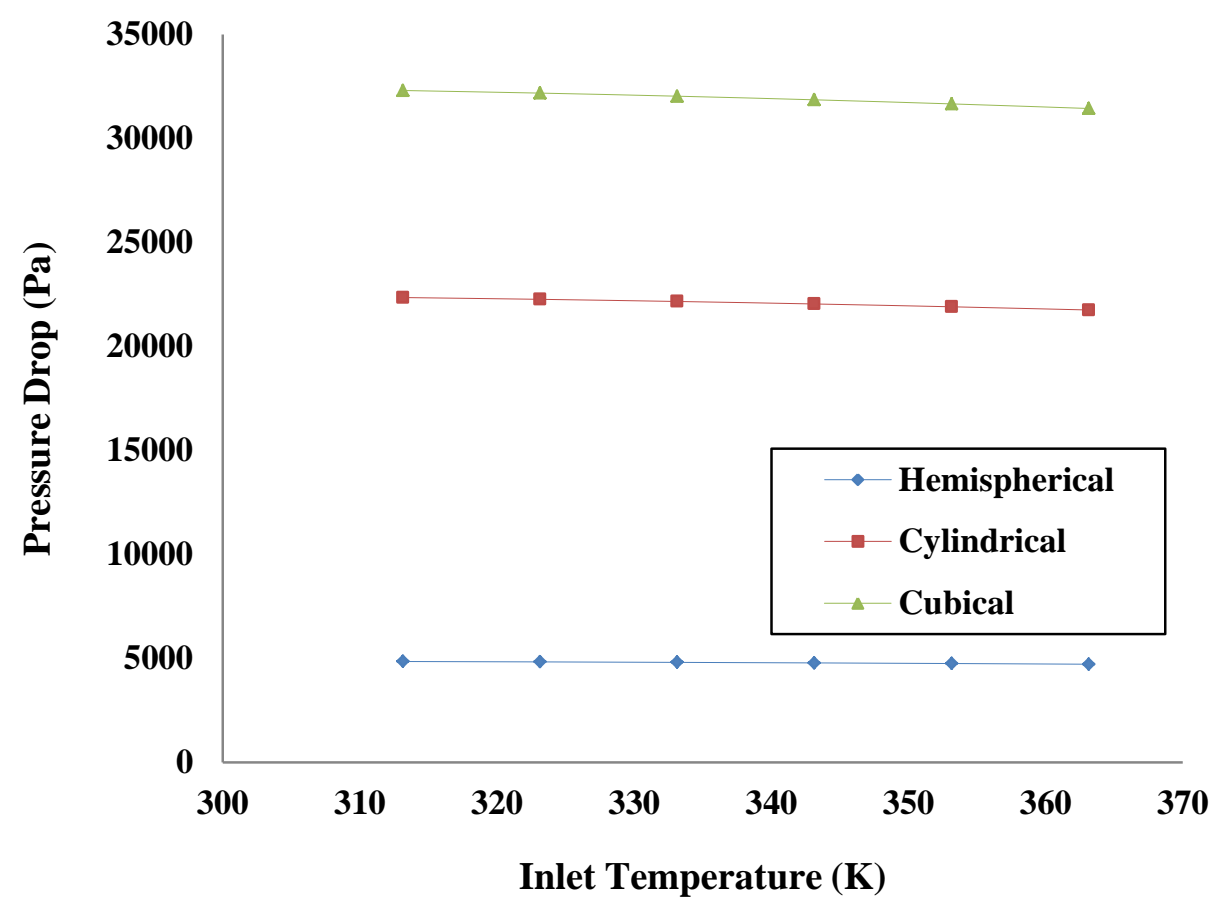

Figure 10. Pressure drop of the cavity receivers with water.

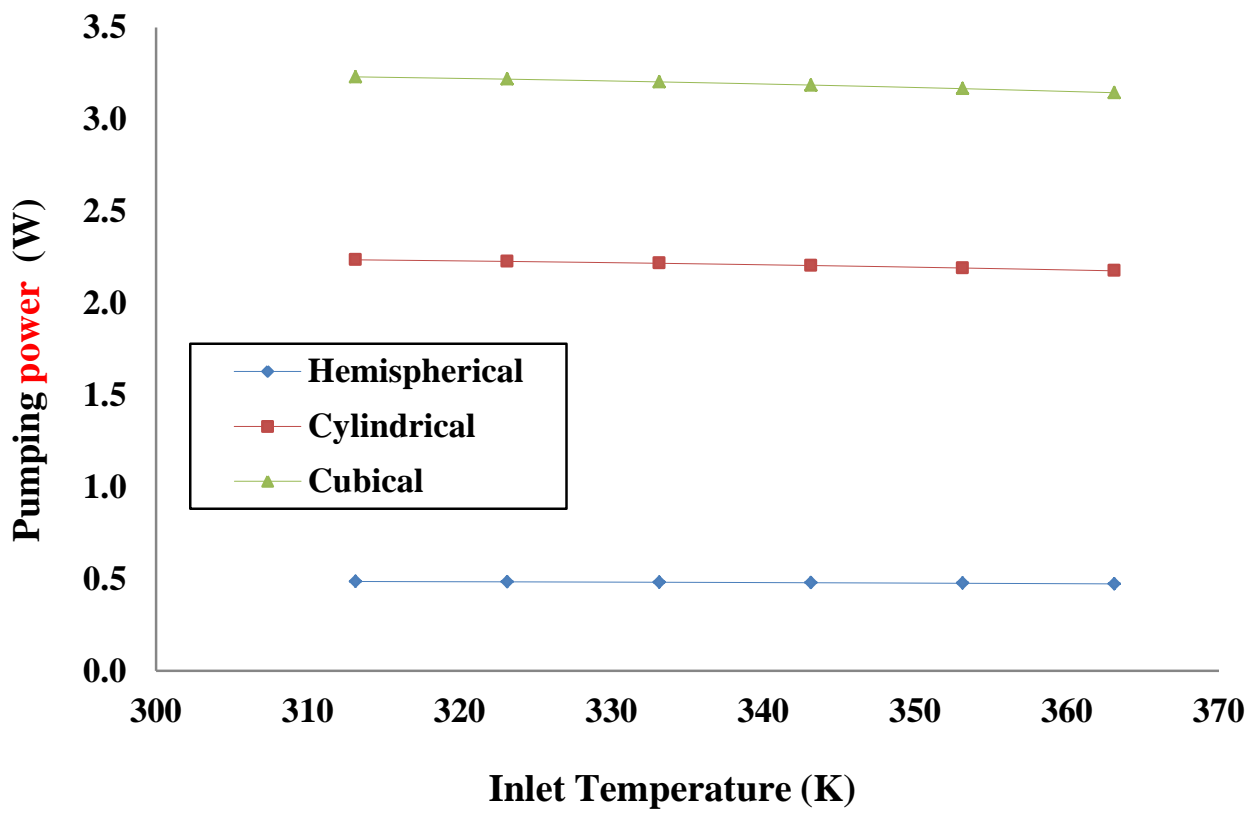

Figure 11. Pumping power required for the cavity receivers with water.

The next step in this analysis is the evaluation of the exergetic efficiency and the overall system efficiency, which are given in Figures 12 and 13, respectively. Figure 12 shows that the hemispherical cavity has the highest exergetic efficiency. It is useful to state that in low temperatures, the hemispherical and the cubical cavities have similar exergetic performances. 
Also, the hemispherical cavity has the highest overall efficiency for temperatures above $335 \mathrm{~K}$, according to Figure 13. The overall efficiency is close to the thermal efficiency because of the low pumping power required. On the other hand, the exergetic efficiency is lower and ranges from less than $4 \%$ to $13.3 \%$.

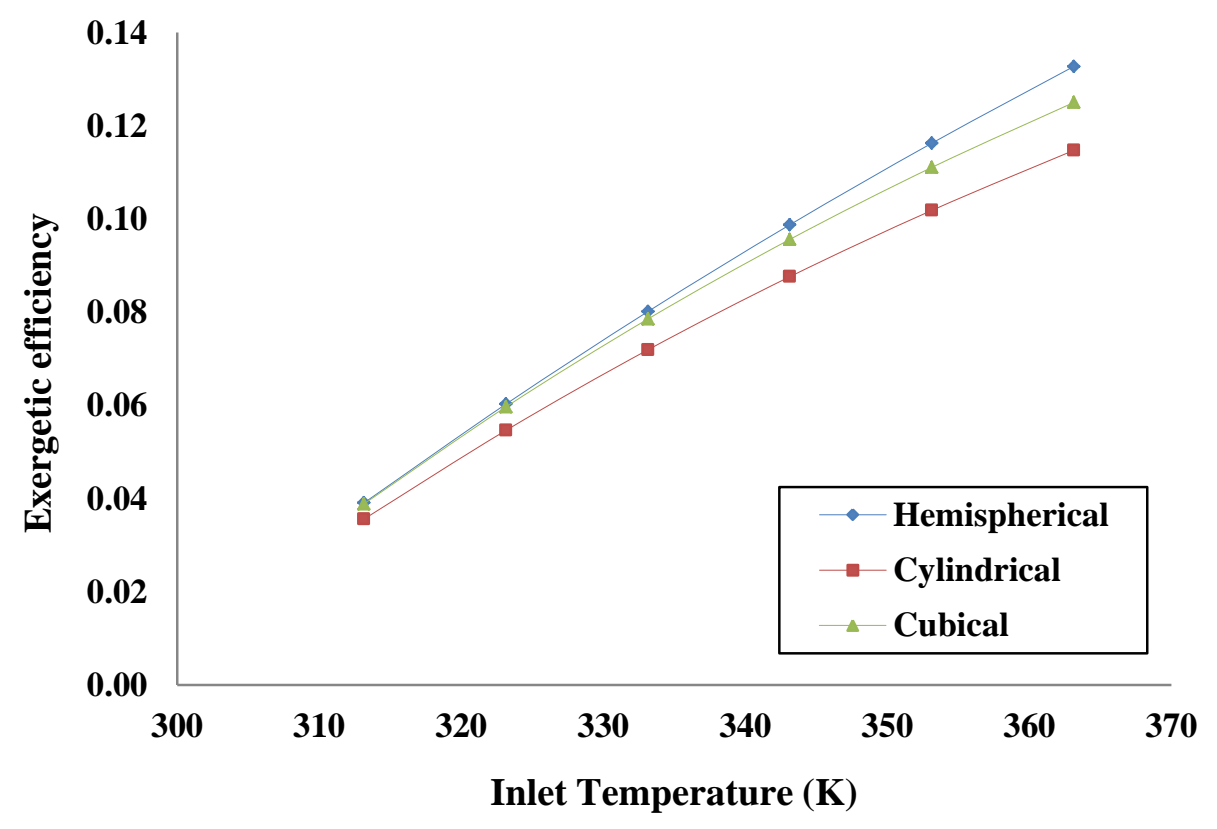

Figure 12. Exergetic efficiency of the cavity receivers with water.

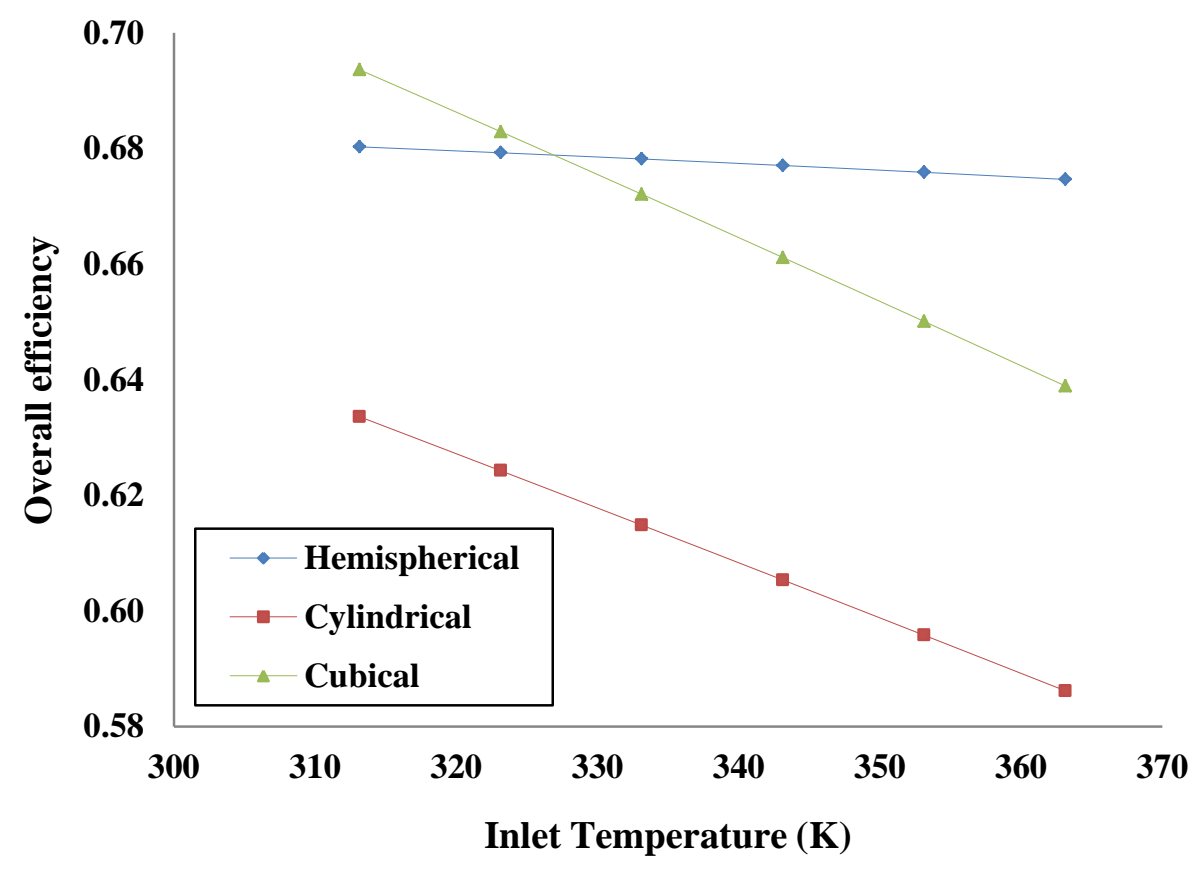

Figure 13. Overall efficiency of the cavity receivers with water. 


\subsubsection{Results for operation with thermal oil}

In this section, the operation of the cavity receivers with thermal oil as working fluid is considered. Note that the results were obtained for a direct normal solar irradiance of $800 \mathrm{~W} / \mathrm{m}^{2}$ and a flow rate of $100 \mathrm{ml} / \mathrm{s}$, as shown in Table 4. For this case, the solar dish collector is operating at medium to high temperatures, which are more common for solar dishes. The same operating conditions as in Subsection 4.2.1 have been used in order to compare both working fluids.

Similar to the previous section, the thermal efficiency of the collector is shown in Figure 14 and the useful heat production in Figure 15. Results show that the hemispherical cavity receiver performs the best, followed by the cubical and cylindrical cavity receivers. Note that for high temperatures close to $570 \mathrm{~K}$, the cylindrical cavity receiver has a higher efficiency than the cubical cavity receiver. Moreover, it is important to state that at high temperatures, the hemispherical receiver presents extremely higher performance than the other two cases, which makes this cavity a promising choice for high-temperature applications. This result can be attributed to the fact that the hemispherical cavity receiver has a smaller outer surface area exposed to the environment, and consequently, less conduction heat loss.

The pressure drop is shown in Figure 16 and the pumping power in Figure 17. The pressure drop reaches values of up to $28000 \mathrm{~Pa}$, while the pumping power reaches values of up to $2.8 \mathrm{~W}$. The cubical cavity receiver has the highest pressure drop followed by the cylindrical and the hemispherical cavity receivers. The obtained pressure drops are relatively high but the pumping power consumption is low. This result proves that the pressure drop is not an important limitation of the examined configurations. 


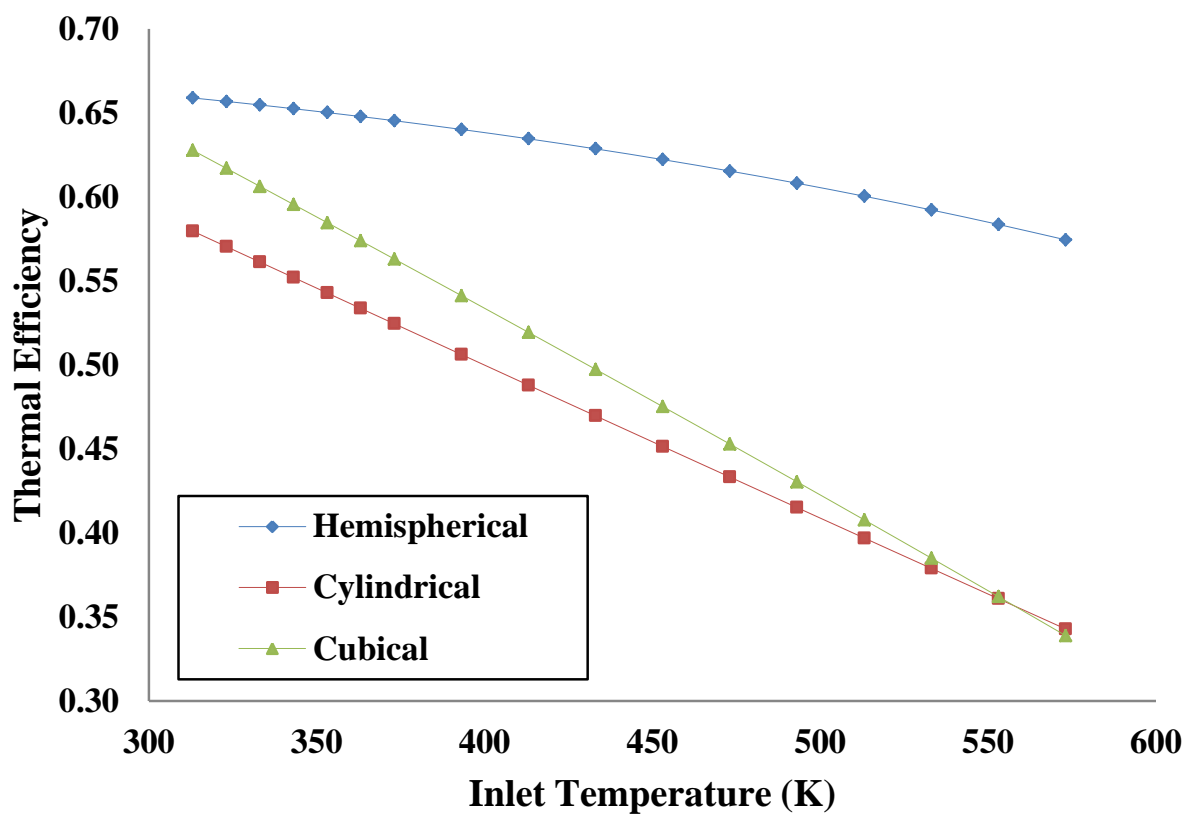

Figure 14. Thermal efficiency of the cavity receivers with thermal oil.

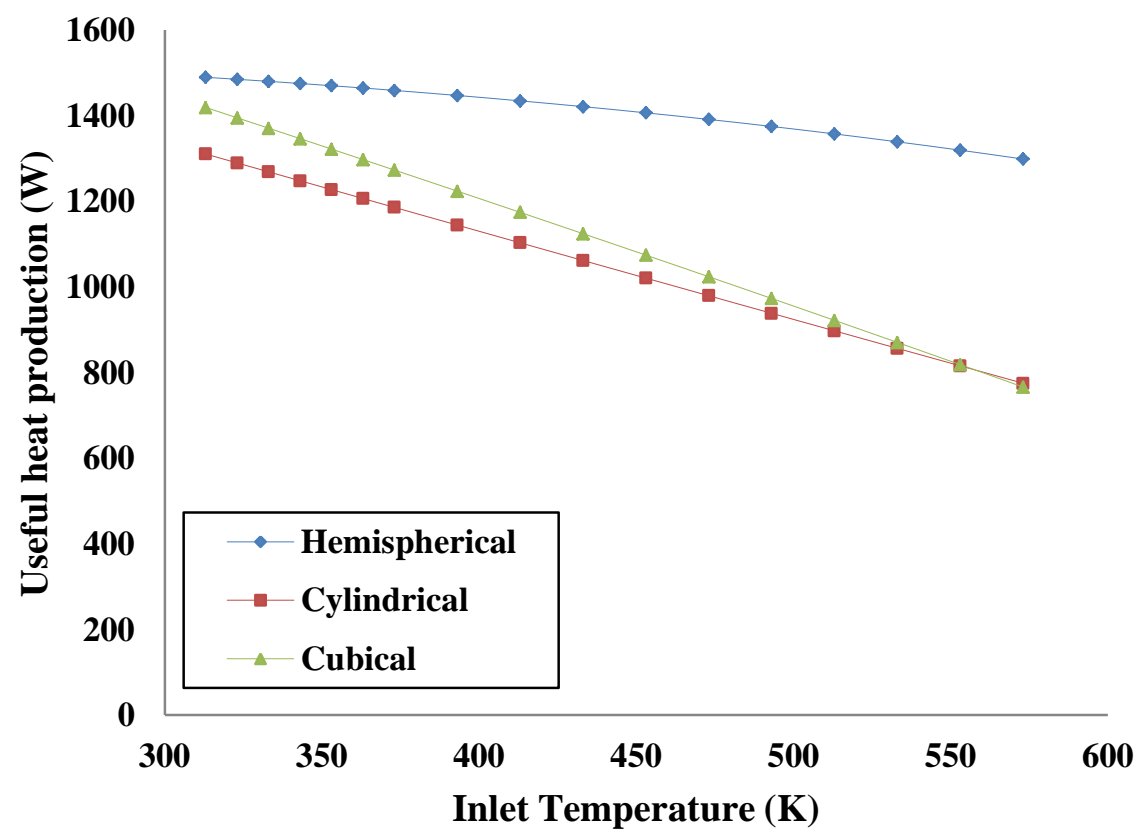

Figure 15. Useful heat production of the cavity receivers with thermal oil. 


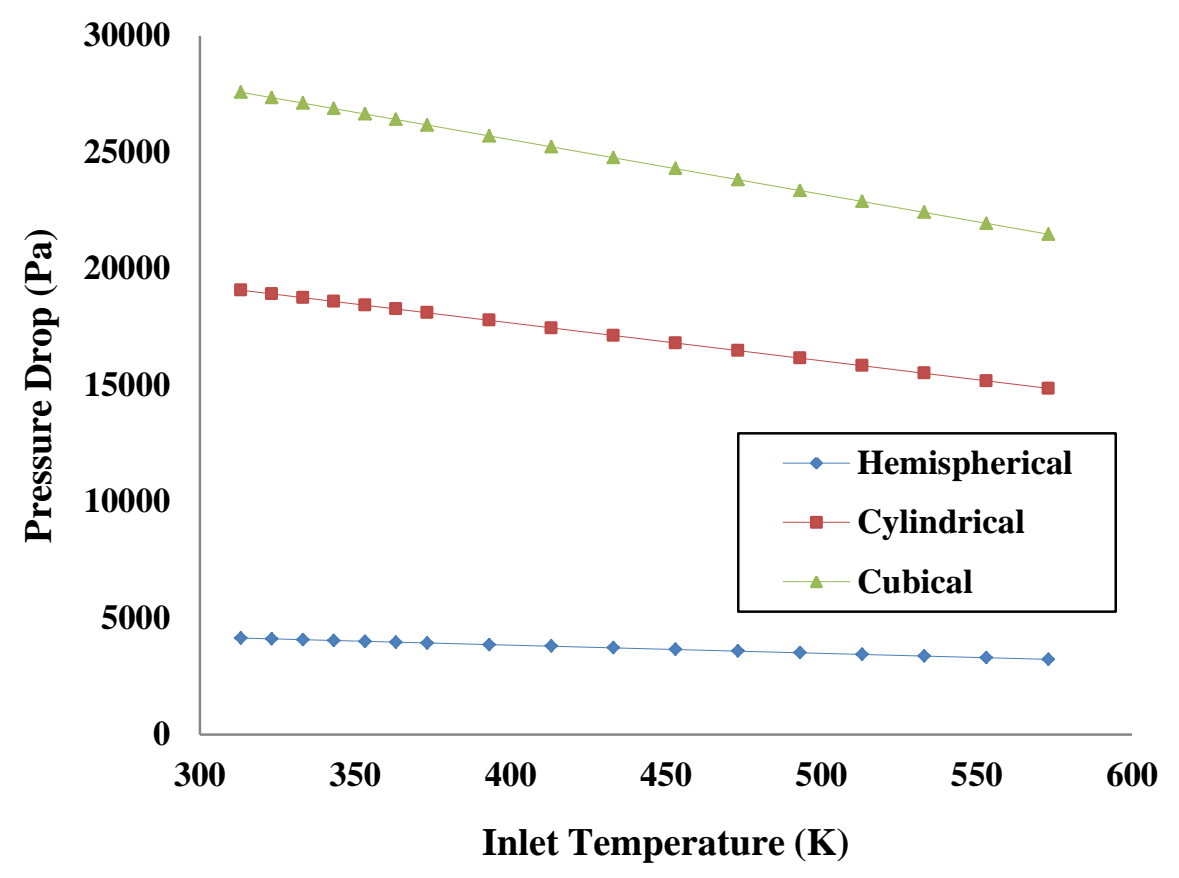

Figure 16. Pressure drop of the cavity receivers with thermal oil.

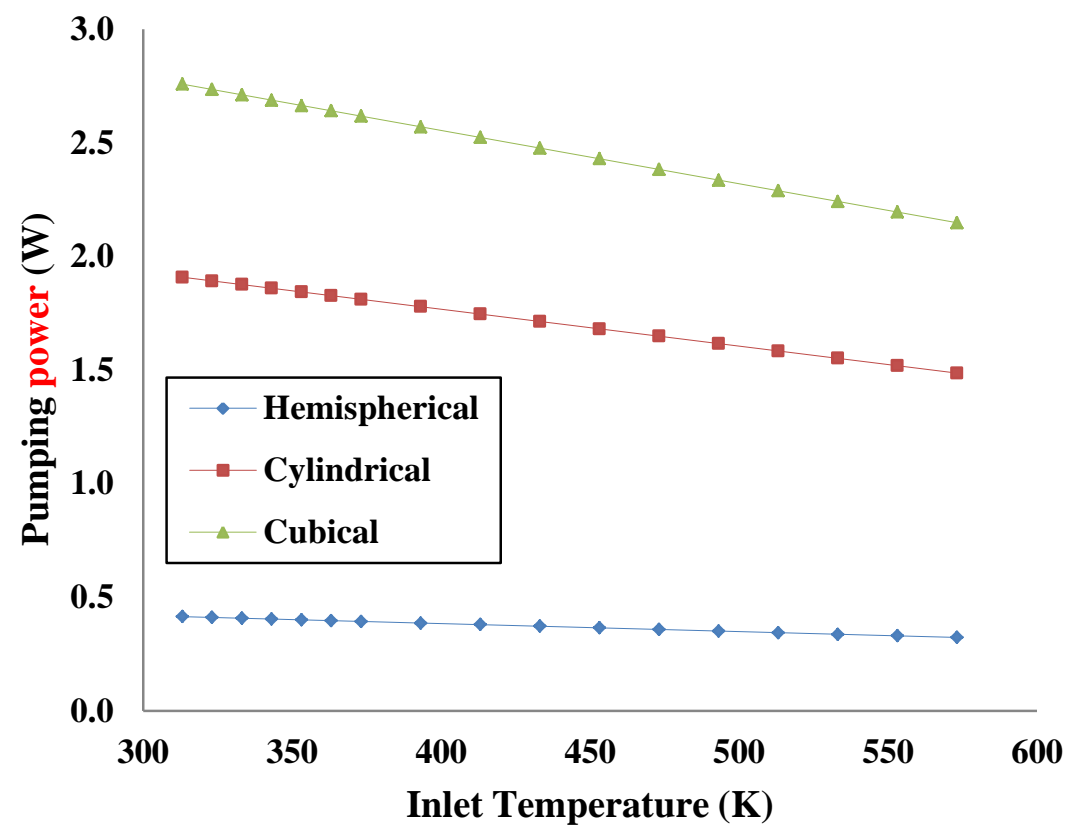

Figure 17. Pumping power of the cavity receivers with thermal oil.

The exergetic comparison in Figure 18 confirms that the hemispherical cavity performs the best and that this cavity is suitable for high-temperature applications. For the hemispherical cavity, the maximum exergetic efficiency is about $30 \%$ for an inlet temperature of $575 \mathrm{~K}$. This is a relatively high value which indicates a high potential for power generation using solar dishes 
coupled to thermal engines. Furthermore, it is important to state that the maximum exergetic efficiency with thermal oil is higher than with water because the thermal oil is able to operate at higher temperatures.

Figure 19 also shows that the hemispherical cavity has the highest overall efficiency. The overall efficiency has similar values to the thermal efficiency because of the low pumping power consumption. It is essential to state that the results of thermal and overall efficiency indicate that the hemispherical design is the proper choice for operating at high temperatures, because of the small negative slopes of the efficiency curves.

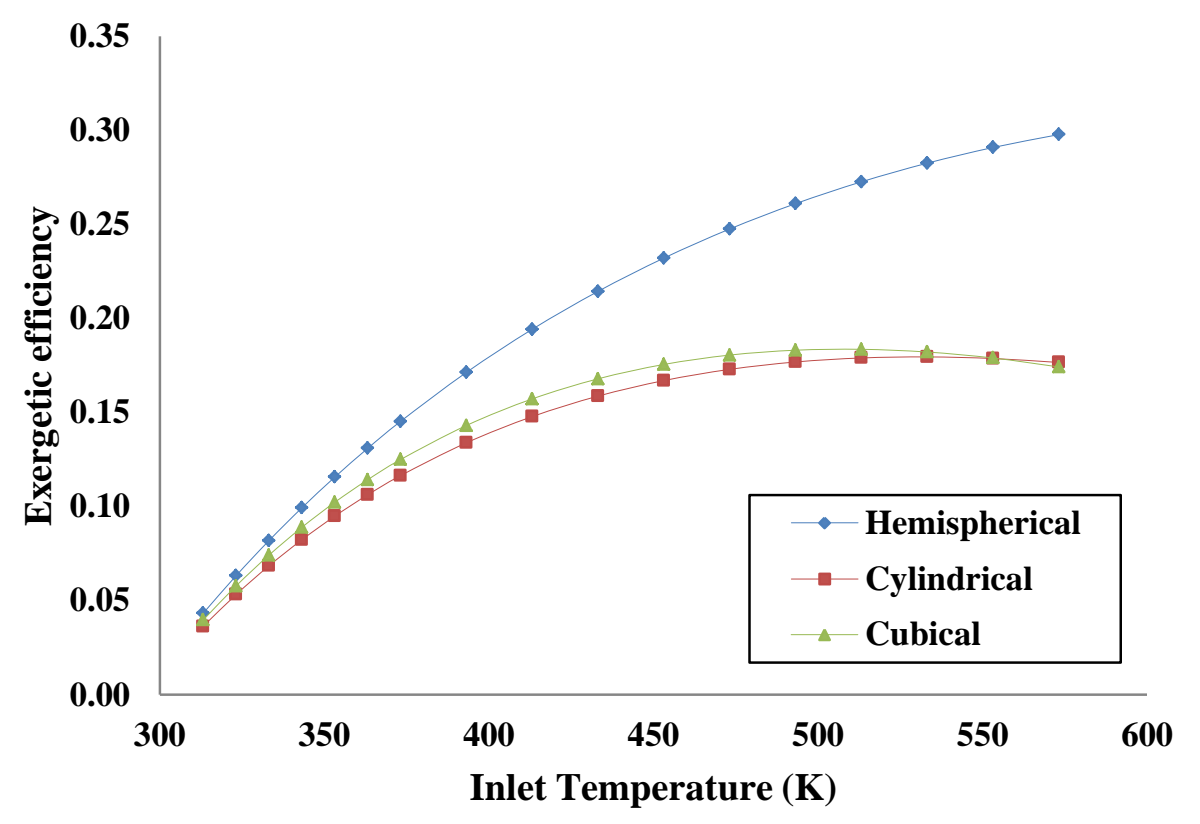

Figure 18. Exergetic efficiency of the cavity receivers with thermal oil. 


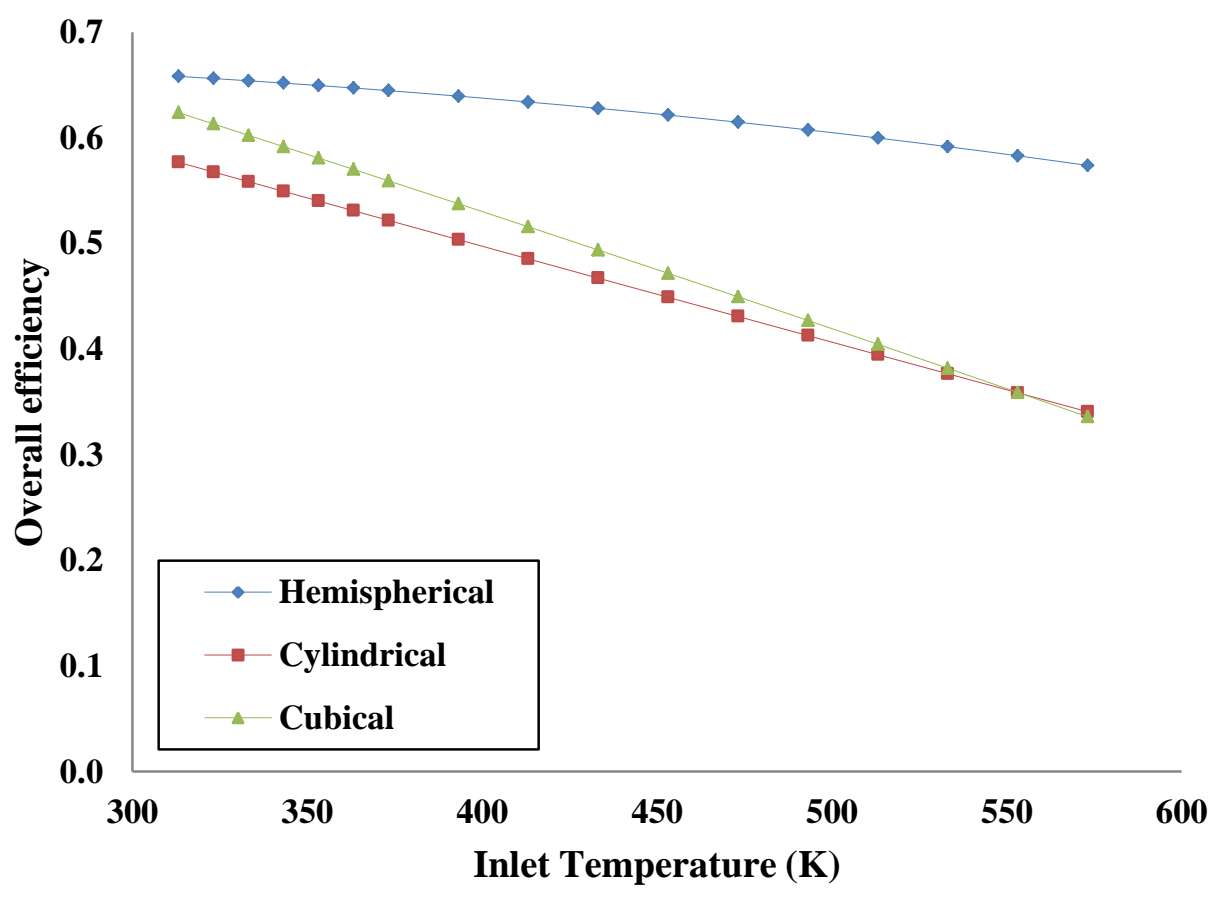

Figure 19. Overall efficiency of the cavity receivers with thermal oil.

\subsection{Comparison of the working fluids - discussion}

In this section, the performance of the collector with water and thermal oil is compared. The thermal efficiency and the pumping power are shown in Figures 20 and 21, respectively. Figure 20 indicates that the use of water leads to higher thermal efficiency compared to thermal oil. This is as a result of the difference in thermal properties of the two fluids. Figure 21 shows that the use of water leads to higher pumping power. However, the pumping power is small compared to the heat gain. This comparative analysis shows that for low-temperature applications, water is the best working fluid, while for higher temperature applications (over $90^{\circ} \mathrm{C}$ ) thermal oil has to be selected. The main reason for the lower performance of the thermal oil is based on the relatively low thermal conductivity of thermal oil compared to water (see Figure A3) and to the lower product of density-specific heat capacity (or volumetric specific heat capacity) of the thermal oil, as discussed in Appendix A.

At the end of this section, it is essential to state that this study proved that the hemispherical design is the best case for solar dish collectors. Moreover, Shuai et al. [30-31] have also found that this is the optimum design for solar dish collectors. The obtained results are thus reasonable and in accordance with the existing trends in literature.

In another work, Stefanovic et al. [51] found the maximum exergetic efficiency of a solar dish collector with spiral absorber to be about $21 \%$ for operation at $212^{\circ} \mathrm{C}$ with thermal oil, a value which is lower than the exergetic efficiency of the suggested design. It is thus clear that the results of this work indicate that the hempispherical cavity receiver is a more efficient system. 


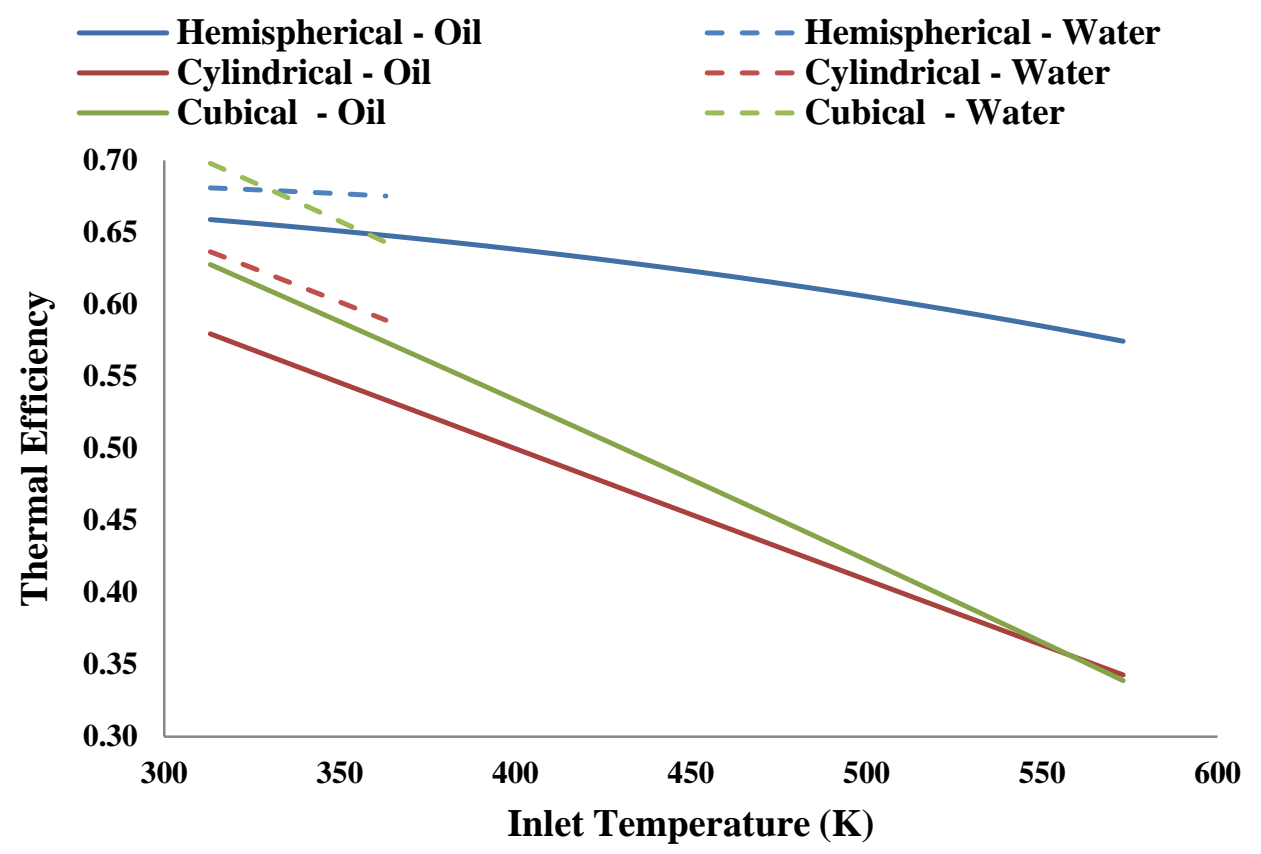

Figure 20. Thermal efficiency comparison between the cavity receivers and the working fluids.

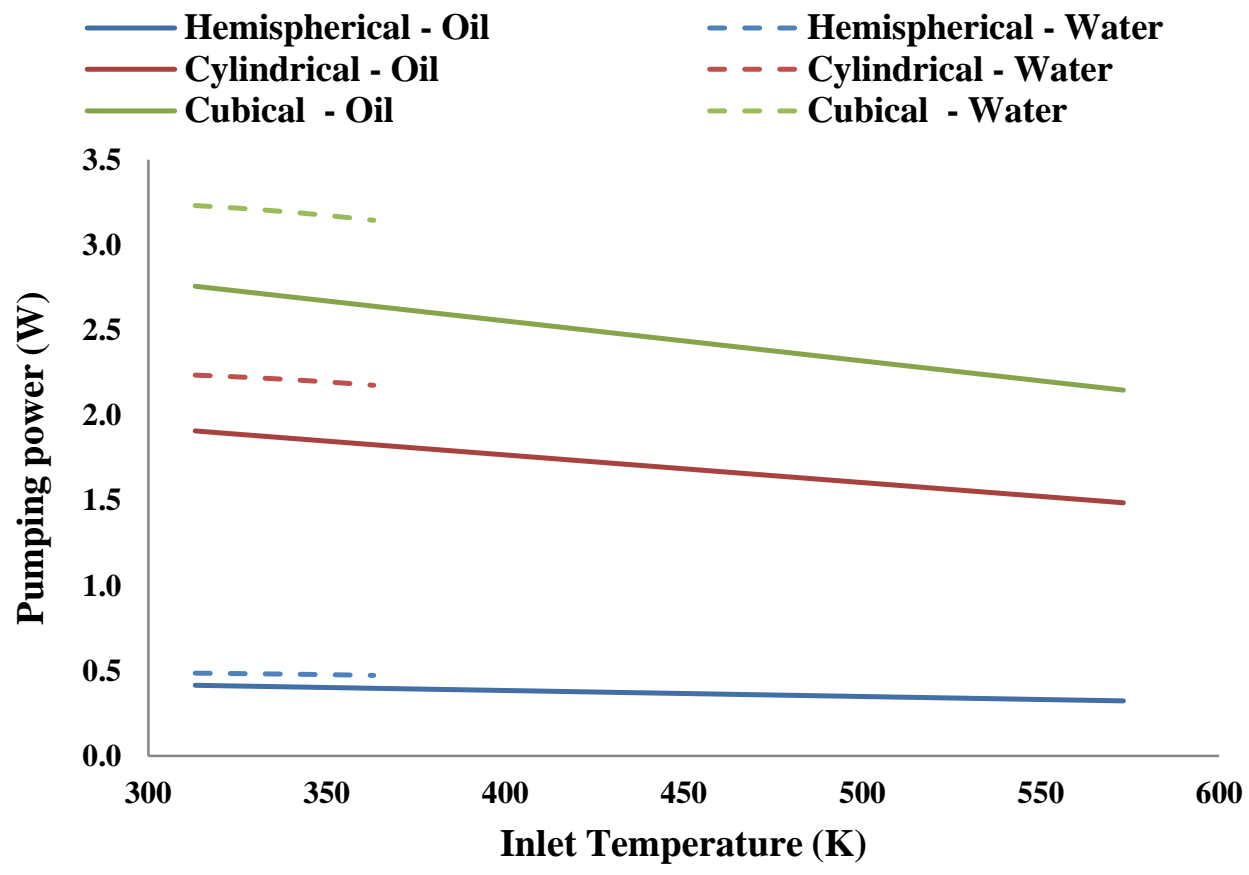

Figure 21. Pumping power comparison between the cavity receivers and the working fluids. 


\section{Conclusions}

The objective of this study was to compare three different cavities in a solar dish collector for operation with water and Behran oil up to temperatures of $90^{\circ} \mathrm{C}$ and $300^{\circ} \mathrm{C}$ respectively. A hemispherical, a cylindrical and a cubical cavity receiver were investigated under the same operating conditions using a numerical model. The numerical model was validated with experimental results of the hemispherical cavity. The most important results of this work are listed below:

- The hemispherical cavity receiver is found to be the appropriate cavity for the majority of inlet temperatures for both working fluids, according to the thermal efficiency. The second most appropriate is the cubical cavity, which is followed by the cylindrical cavity.

- According to the exergetic efficiency, the hemispherical cavity is also the best case, followed by the cubical and cylindrical cavities. However, it is important to state that the cubical and the cylindrical cavities have similar exergetic performances.

- The cubical cavity receiver presents the highest pressure drop, followed by the cylindrical and the hemispherical cavities.

- The obtained values of the pumping power are relatively low, showing that the electricity consumption of the pumping system is insignificant when compared to the useful heat gain.

- In low-temperature applications, water is found to be the best working fluid, because it has better thermal properties compared to thermal oil.

- Lastly, the high exergetic efficiency (about 30\%) of the hemispherical cavity receiver with thermal oil at high temperatures is a promising result for the establishment of solar dishes in thermal power generation applications.

\section{Nomenclature}

A Area, $\mathrm{m}^{2}$

$c_{2}$ Constant used in the linear equation, $\mathrm{W} / \mathrm{m}^{2}$

$\mathrm{c}_{\mathrm{p}} \quad$ Specific heat capacity, J/kg K

D Diameter, $m$

d Receiver tube diameter, $\mathrm{m}$

$\dot{E} \quad$ Exergy flow, $\mathrm{W}$

$F_{n-j} \quad$ View factor between surface $n$ and surface $j$, -

$f_{r} \quad$ Friction factor, - 
g Earth gravity, $\mathrm{m} / \mathrm{s}^{2}$

Gr Grashof number, -

h Heat transfer coefficient, W/m $/ \mathrm{m}^{2} \mathrm{~K}$

$\mathrm{I}_{\text {sun }} \quad$ Solar direct beam irradiation, $\mathrm{W} / \mathrm{m}^{2}$

k Thermal conductivity, W/mK

K Pressure loss coefficient, -

L Length of cavity tube, m

$\mathrm{m}_{2} \quad$ Slope of linear equation, $\mathrm{W} / \mathrm{m}^{2} \mathrm{~K}$

$\dot{\mathrm{m}} \quad$ System mass flow rate, $\mathrm{kg} / \mathrm{s}$

$\mathrm{Nu} \quad$ Nusselt number, -

Pr Prandtl number, -

$\dot{\mathrm{Q}}_{\text {loss }}$ Loss rate of heat loss from the cavity receiver, $\mathrm{W}$

$\dot{\mathrm{Q}}_{\text {net }} \quad$ Net heat transfer rate, $\mathrm{W}$

$\dot{\mathrm{Q}}_{\text {solar }}$ Rate of available solar heat at dish concentrator, W

$\dot{\mathrm{Q}}^{*} \quad$ Rate of available solar heat at receiver cavity, $\mathrm{W}$

$\mathrm{R}$ Thermal resistance, $\mathrm{m}^{2} \mathrm{~K} / \mathrm{W}$

Ra Rayleigh number, -

Re Reynolds number, -

T Temperature, ${ }^{\circ} \mathrm{C}$

t Thickness, $\mathrm{mm}$

Pr Prandtl number

V Volumetric flow rate, $\mathrm{ml} / \mathrm{s}$

$\mathrm{V}_{\text {wind }}$ Wind speed, $\mathrm{m} / \mathrm{s}$

$\dot{\mathrm{W}}_{\text {pump }}$ Pumping power, $\mathrm{W}$

\section{Greek symbols}


$\beta \quad$ Coefficient of thermal expansion, $\mathrm{K}^{-1}$

$\Delta \mathrm{P} \quad$ Pressure drop, $\mathrm{Pa}$

$\varepsilon \quad$ Emittance, -

$\eta \quad$ Efficiency, -

$\theta \quad$ Cavity inclination angle, ${ }^{\circ}$

$\mu \quad$ Dynamic viscosity, Pa s

$v \quad$ Kinematic viscosity of the fluid, $\mathrm{m}^{2} / \mathrm{s}$

$\rho \quad$ Density, $\mathrm{kg} / \mathrm{m}^{3}$

$\sigma \quad$ Stefan-Boltzmann constant, $\mathrm{W} / \mathrm{m}^{2} \mathrm{~K}^{4}$

\section{Subscripts and superscripts}

ap aperture of the cavity

Ave average

conc concentrator

conv convection

cond conduction

D diameter

el electrical equivalent

f working fluid

forced forced convection

j cavity tube element

inner inner of cavity tube

inlet inlet

ins insulation

n tube section number

natural natural convection 


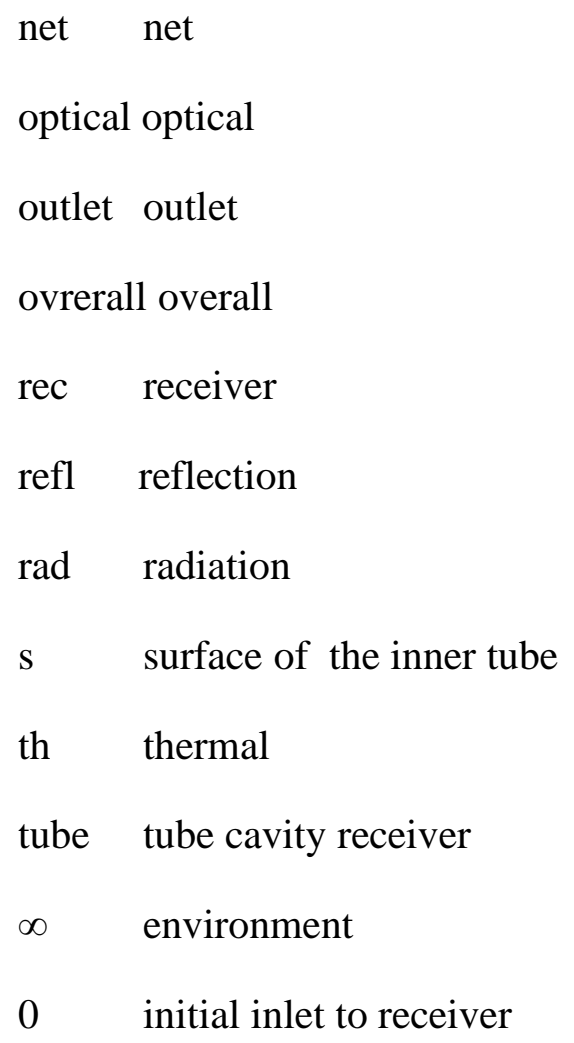

\section{Appendix A - Thermal properties of the examined fluids}

The thermal properties of Behran oil are calculated based on Ref. [36]. The thermal properties of water have been taken from Ref. [50]. Figures A1-A4 give the density, the specific heat capacity, the thermal conductivity and the viscosity of the examined fluids.

Figure A1 indicates that the density decreases as the temperature increases, while the thermal oil has lower density than water. Figure A2 shows that the specific heat capacity increases with temperature and that water has higher specific heat capacity than thermal oil. The results of Figures A1 and A2 prove that water is a better heat transfer fluid than thermal oil, because of higher density and higher specific heat capacity and therefore it is able to carry more heat for the same volumetric flow rate. Figure A3 depicts the thermal conductivity which increases with temperature for water, while the thermal oil has the opposite behavior. Moreover, it is important to note that thermal oil has about four times lower thermal conductivity compared to water, a fact that makes heat transfer from the warm tube to the tube core difficult. Finally, Figure A4 illustrates the dynamic viscosity which decreases as the temperature increases. It is important to state that the dynamic viscosity of the thermal oil is about five times greater than for water, a fact that increases the pumping power for oil. 
This section shows that water is a better working fluid than thermal oil, because it can carry more heat with a lower pressure drop. However, the use of thermal oil is necessary for operating at temperatures of over $100^{\circ} \mathrm{C}$ and up to $300^{\circ} \mathrm{C}$.

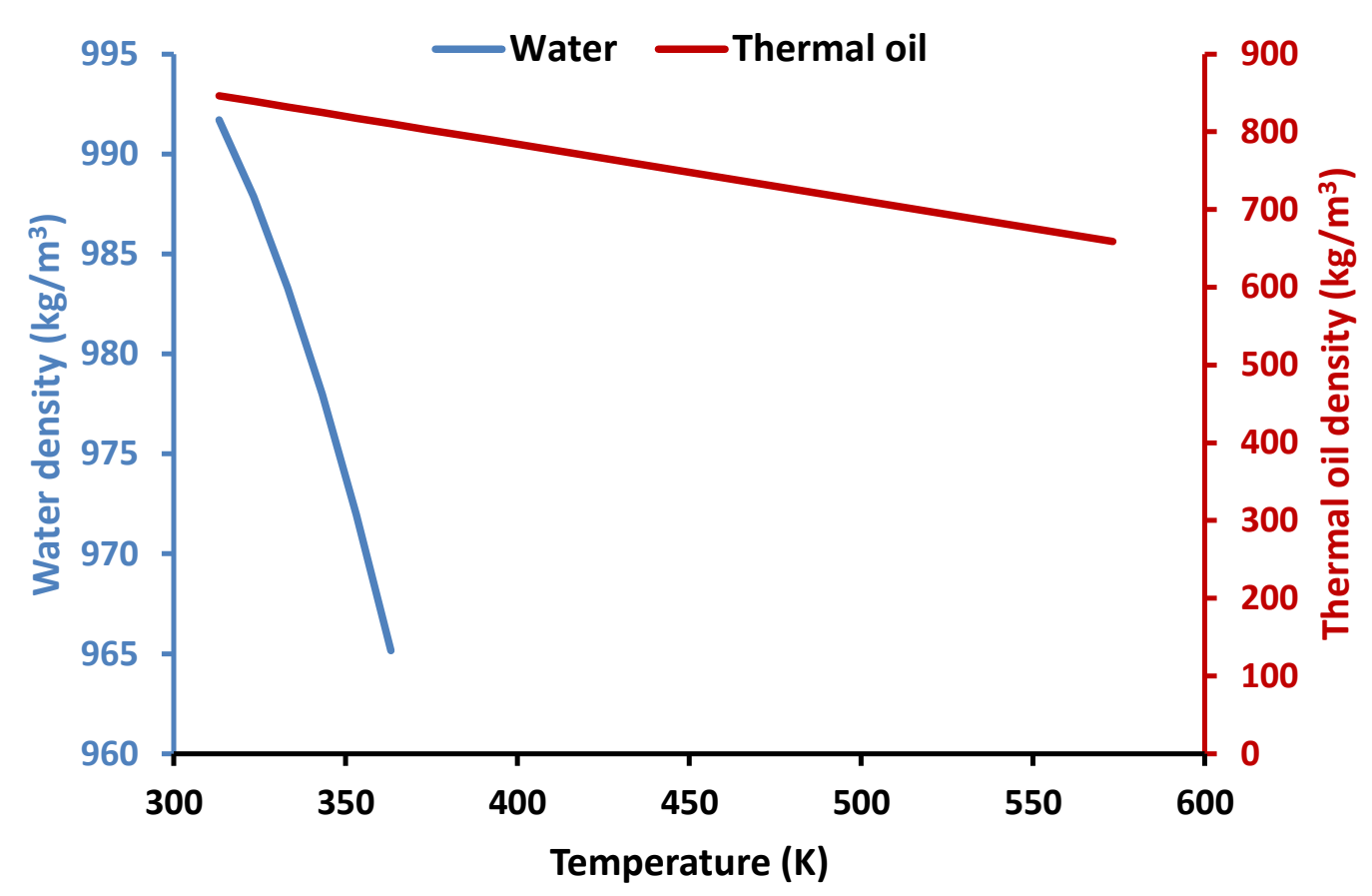

Figure A1. Density of the working fluids.

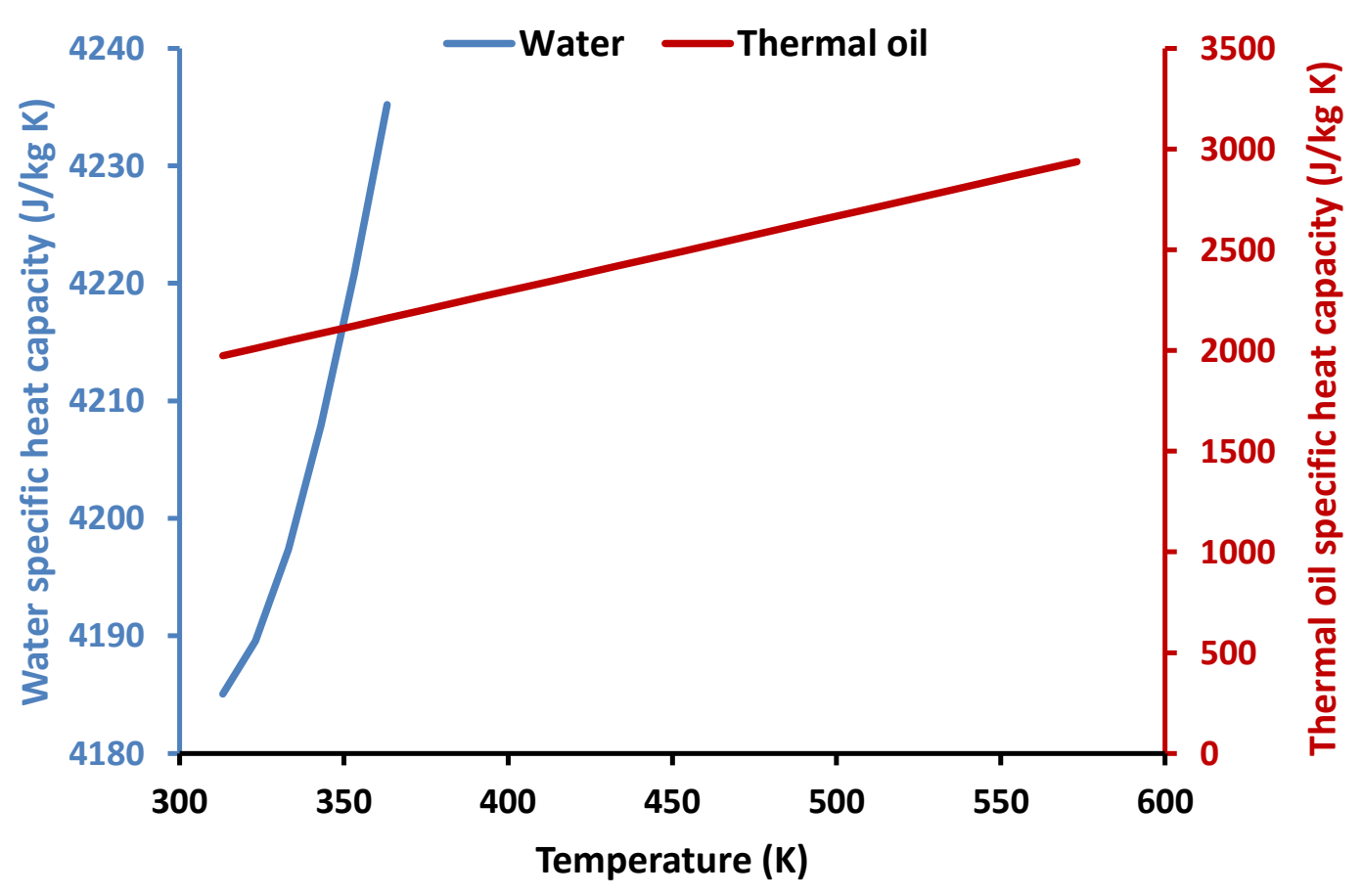


Figure A2. Specific heat capacity of the working fluids.

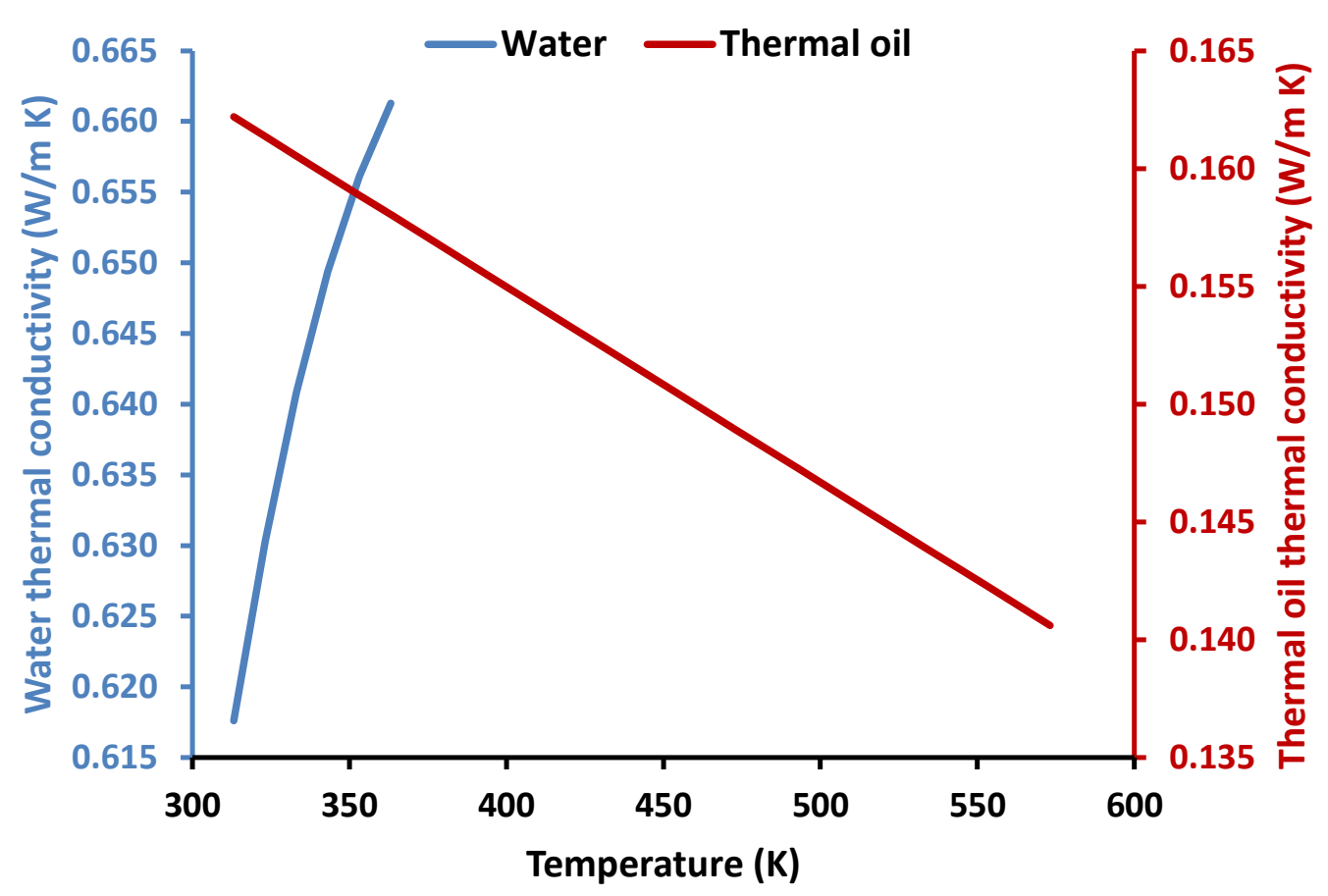

Figure A3. Thermal conductivity of the working fluids.

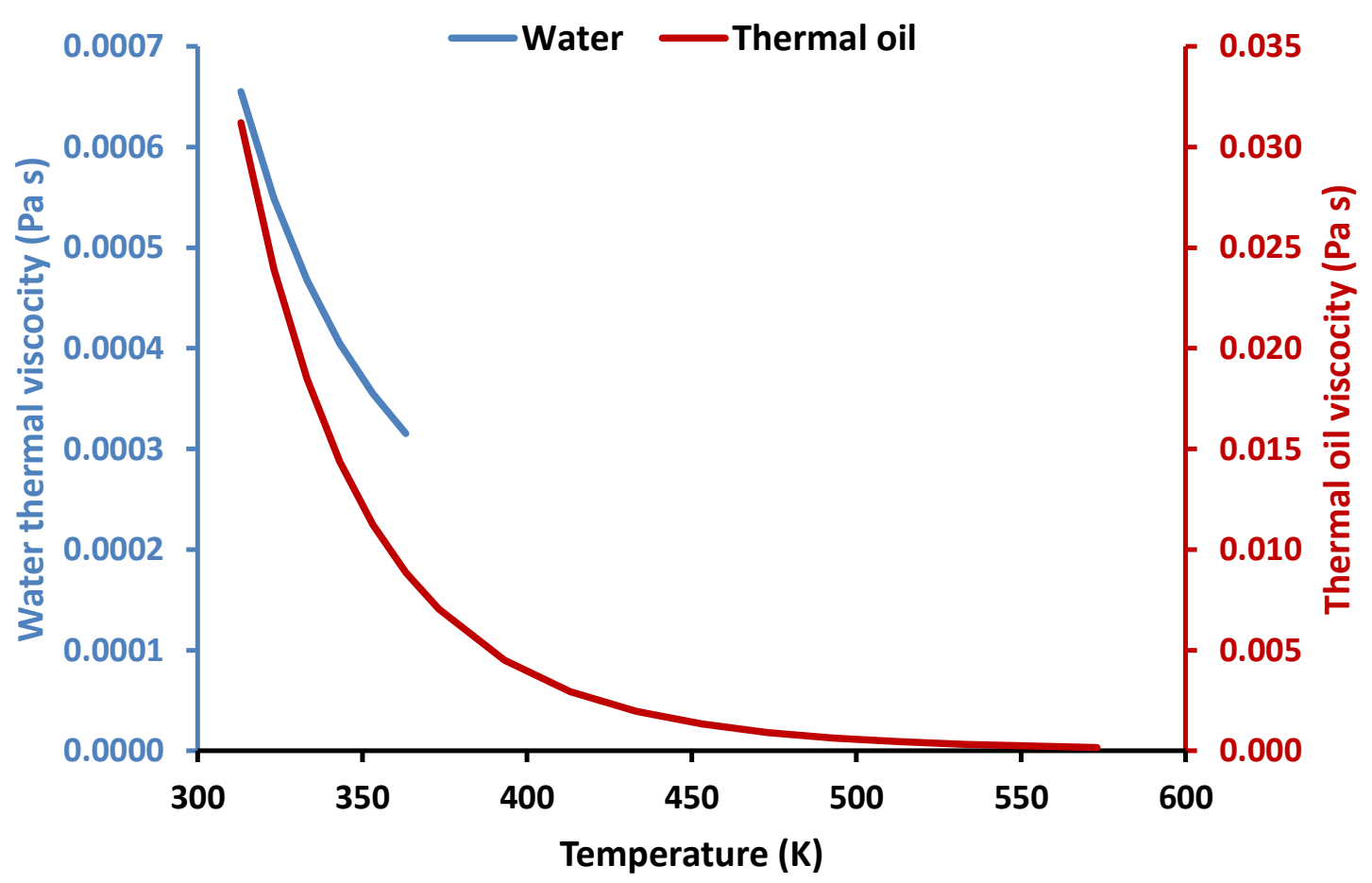




\section{Figure A4. Viscosity of the working fluids.}

\section{References}

[1] M.Z. Stijepovic, A.I. Papadopoulos, P. Linke, V. Stijepovic, A.S. Grujic, M. Kijevčanin, P. Seferlis, Organic Rankine Cycle system performance targeting and design for multiple heat sources with simultaneous working fluid selection, Journal of Cleaner Production 2017;142:1950-1970.

[2] B. Jamil, N. Akhtar, Comparative analysis of diffuse solar radiation models based on skyclearness index and sunshine period for humid-subtropical climatic region of India: A case study, Renewable and Sustainable Energy Reviews 2017;78:329-355.

[3] A. Kasaeian, R. Daneshazarian, R. Rezaei, F. Pourfayaz, G. Kasaeian, Experimental investigation on the thermal behavior of nanofluid direct absorption in a trough collector, Journal of Cleaner Production 2017;158:276-284.

[4] M. Esen, H. Esen, Experimental investigation of a two-phase closed thermosyphon solar water heater, Solar Energy 2005;79(5):459-468

[5] M. Esen, Thermal performance of a solar cooker integrated vacuum-tube collector with heat pipes containing different refrigerants, Solar Energy 2004;76(6):751-757

[6] J. Coventry, C. Andraka, Dish systems for CSP, Solar Energy 2017;152:140-170.

[7] A. Mohammadi, M. Mehrpooya, Exergy analysis and optimization of an integrated micro gas turbine, compressed air energy storage and solar dish collector process, Journal of Cleaner Production 2016;139:372-383.

[8] M. Schmitz, G. Ambrosetti, T. Cooper, A. Steinfeld, On-sun optical characterization of a solar dish concentrator based on elliptical vacuum membrane facets, Solar Energy 2017;153:732743.

[9] S. Cohen, G. Grossman, Development of a solar collector with a stationary spherical reflector/tracking absorber for industrial process heat, Solar Energy 2016;128:31-40.

[10] M. Chandrashekara, A. Yadav, An experimental study of the effect of exfoliated graphite solar coating with a sensible heat storage and Scheffler dish for desalination, Applied Thermal Engineering 2017;123:111-122.

[11] T. Yu, Q. Yuan, J. Lu, J. Ding, Y. Lu, Thermochemical storage performances of methane reforming with carbon dioxide in tubular and semi-cavity reactors heated by a solar dish system, Applied Energy 2017;185(2):1994-2004. 
[12] J. Wang, S. Yang, C. Jiang, Q. Yan, P.D. Lund, A novel 2-stage dish concentrator with improved optical performance for concentrating solar power plants, Renewable Energy 2017;108:92-97.

[13] E. Przenzak, M. Szubel, M. Filipowicz, The numerical model of the high temperature receiver for concentrated solar radiation, Energy Conversion and Management 2016;125:97-106.

[14] R. Loni, A.B. Kasaeian, E. Askari Asli-Ardeh, B. Ghobadian, Optimizing the efficiency of a solar receiver with tubular cylindrical cavity for a solar-powered organic Rankine cycle, Energy 2016;112:1259-1272.

[15] C. Zou, Y. Zhang, Q. Falcoz, P. Neveu, C. Zhang, W. Shu, S. Huang, Design and optimization of a high-temperature cavity receiver for a solar energy cascade utilization system, Renewable Energy 2017;103:478-489.

[16] M. Prakash, S.B. Kedare, J.K. Nayak, Investigations on heat losses from a solar cavity receiver, Solar Energy 2009;83(2):157-170.

[17] A. Mawire, S.H. Taole, Experimental energy and exergy performance of a solar receiver for a domestic parabolic dish concentrator for teaching purposes, Energy for Sustainable Development 2014;19:162-169.

[18] D. Azzouzi, B. Boumeddane, A. Abene, Experimental and analytical thermal analysis of cylindrical cavity receiver for solar dish, Renewable Energy 2017;106:111-121.

[19] Y. Tan, L. Zhao, J. Bao, Q. Liu, Experimental investigation on heat loss of semi-spherical cavity receiver, Energy Conversion and Management 2014;87:576-583.

[20] K.S. Reddy, T.S. Vikram, G. Veershetty, Combined heat loss analysis of solar parabolic dish - modified cavity receiver for superheated steam generation, Solar Energy 2015;121:78-93

[21] K.S. Reddy, G. Veershetty, T. Srihari Vikram, Effect of wind speed and direction on convective heat losses from solar parabolic dish modified cavity receiver, Solar Energy 2016;131:183-198.

[22] S. Pavlovic, E. Bellos, W.G. Le Roux, V. Stefanovic, C. Tzivanidis, Experimental investigation and parametric analysis of a solar thermal dish collector with spiral absorber, Applied Thermal Engineering 2017;121:126-135.

[23] S. Pavlovic, A.M. Daabo, E. Bellos, V. Stefanovic, S. Mahmoud, R.K. Al-Dadah, Experimental and numerical investigation on the optical and thermal performance of solar parabolic dish and corrugated spiral cavity receiver, Journal of Cleaner Production 2017;150:7592. 
[24] S.R. Pavlović, E. Bellos, V.P. Stefanović, C. Tzivanidis, Z.M. Stamenković, Design, simulation and optimization of a solar dish collector spiral-coil thermal absorber, Thermal Science 2016;20(4):1387-1397.

[25] R. Loni, A.B. Kasaeian, E. Askari Asli-Ardeh, B. Ghobadian, W.G. Le Roux, Performance study of a solar-assisted organic Rankine cycle using a dish-mounted rectangular-cavity tubular solar receiver, Applied Thermal Engineering 2016;108:1298-1309.

[26] R. Loni, A.B. Kasaeian, O. Mahian, A.Z. Sahin, Thermodynamic analysis of an organic rankine cycle using a tubular solar cavity receiver, Energy Conversion and Management 2016;127:494-503.

[27] G. Xu, Y. Wang, Y. Quan, H. Li, S. Li, G. Song, W. Gao, Design and characteristics of a novel tapered tube bundle receiver for high-temperature solar dish system, Applied Thermal Engineering 2015;91:791-799.

[28] J. Zhu, K. Wang, G. Li, H.Wu, Z. Jiang, F. Lin, Y. Li, Experimental study of the energy and exergy performance for a pressurized volumetric solar receiver, Applied Thermal Engineering 2016;104:212-221.

[29] P. Wang, J.B. Li, F.W. Bai, D.Y. Liu, C. Xu, L. Zhao, Z.F. Wang, Experimental and theoretical evaluation on the thermal performance of a windowed volumetric solar receiver, Energy 2017;119:652-661.

[30] Y. Shuai, X. Xia, H. Tan, Numerical simulation and experiment research of radiation performance in a dish solar collector system, Front. Energy Power Eng. China 2010;4(4):488495 (DOI 10.1007/s11708-010-0007-z).

[31] Y. Shuai, X.-L. Xia, H.-P. Tan, Radiation performance of dish solar concentrator/cavity receiver systems, Solar Energy 2008;82(1):13-21.

[32] A.M. Daabo, S. Mahmoud, R.K. Al-Dadah, The optical efficiency of three different geometries of a small scale cavity receiver for concentrated solar applications, Applied Energy 2016;179:1081-1096.

[33] A.M. Daabo, S. Mahmoud, R.K. Al-Dadah, The effect of receiver geometry on the optical performance of a small-scale solar cavity receiver for parabolic dish applications, Energy 2016;114:513-525.

[34] R. Loni, E. Askari Asli-Ardeh, B. Ghobadian, A.B. Kasaeian, Sh. Gorjian, Numerical and experimental investigation of wind effect on a hemispherical cavity receiver, Applied Thermal Engineering 2017;126:179-193.

[35] C.E. Kennedy, Review of Mid-to High-temperature Solar Selective Absorber Materials, National Renewable Energy Laboratory, Golden, Colo, USA, 2002. 
[36] A. Baghernejad, M. Yaghoubi, Thermoeconomic methodology for analysis and optimization of a hybrid solar thermal power plant, Int. J. Green Energy 2013;10:588-609.

[37] W.G. Le Roux, T. Bello-Ochende, J.P. Meyer, The efficiency of an open-cavity tubular solar receiver for a small-scale solar thermal Brayton cycle, Energy Conversion and Management, 84 (2014) 457-470.

[38] R.Y. Ma, Wind effects on convective heat loss from a cavity receiver for a parabolic concentrating solar collector, Sandia National Laboratories, 1993.

[39] National Renewable Energy Laboratory, SolTrace, Available at: https://www.nrel.gov/csp/soltrace.html [Last accessed on 3/3/2018].

[40] K.K.S.H. Melcome, A. Mouradian, A. Ajemian, N. Ohan, Technical Information, Pashme Sang Iran, Engineering and Design Department, 2002.

[41] A.Ç. Yunus, J.G. Afshin, Heat and Mass Transfer, McGrawHill, New York, 2007.

[42] K. Reddy, N.S. Kumar, Combined laminar natural convection and surface radiation heat transfer in a modified cavity receiver of solar parabolic dish, Int. J. Therm. Sci. 2008;47:16471657.

[43] N. Kaushika, K. Reddy, Performance of a low cost solar paraboloidal dish steam generating system, Energy Conversion and Management 2000;41:713-726.

[44] H. Esen, M. Inalli, M. Esen, K. Pihtili, Energy and exergy analysis of a ground-coupled heat pump system with two horizontal ground heat exchangers, Building and Environment 2007;42(10):3606-3615

[45] R. Petela, Exergy of undiluted thermal radiation, Solar Energy 2003;74:469-488.

[46] V. Madadi, T. Tavakoli, A. Rahimi, First and second thermodynamic law analyses applied to a solar dish collector, Journal of Non-Equilibrium Thermodynamics 2014;39:183-197.

[47] O. Mahian, A. Kianifar, A.Z. Sahin, S. Wongwises, Performance analysis of a minichannelbased solar collector using different nanofluids, Energy Conversion and Management 2014;88:129-138.

[48] B.R. Munson, D.F. Young, T.H. Okiishi, Fundamentals of fluid mechanics, New York, 3, 1990.

[49] A. Mwesigye, Z. Huan, J.P. Meyer, Thermodynamic optimisation of the performance of a parabolic trough receiver using synthetic oil-A12O3 nanofluid, Applied Energy 2015;156:398412. 
[50] Electrical Research Association, 1967 Steam Tables, Thermodynamic Properties of Water and Steam; Viscosity of Water and Steam, Thermal Conductivity of Water and Steam, Edward Arnold Publishers, London, 1967.

[51] V.P. Stefanovic, S.R. Pavlovic, E. Bellos, C. Tzivanidis, A detailed parametric analysis of a solar dish collector, Sustainable Energy Technologies and Assessments 2018;25:99-110 